\title{
What Antarctic Plants Can Tell Us about Climate Changes: Temperature as a Driver for Metabolic Reprogramming
}

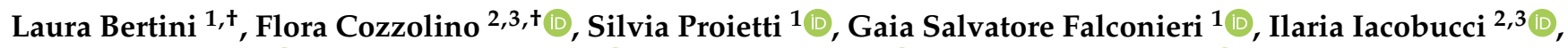 \\ Rosanna Salvia ${ }^{4,5}$, Patrizia Falabella ${ }^{4,5}\left[\right.$, Maria Monti ${ }^{2,3, *(\mathbb{D}}$ and Carla Caruso ${ }^{1, *(1)}$ \\ 1 Department of Ecological and Biological Sciences, University of Tuscia, 01100 Viterbo, Italy; \\ lbertini@unitus.it (L.B.); s.proietti@unitus.it (S.P.); gfalconieri@unitus.it (G.S.F.) \\ 2 Department of Chemical Sciences, University of Naples Federico II, 80126 Naples, Italy; \\ flora.cozzolino@unina.it (F.C.); iacobucci@ceinge.unina.it (I.I.) \\ 3 CEINGE Advanced Biotechnologies, University of Naples Federico II, 80145 Naples, Italy \\ 4 Department of Sciences, University of Basilicata, 85100 Potenza, Italy; r.salvia@unibas.it (R.S.); \\ patrizia.falabella@unibas.it (P.F.) \\ 5 Spinoff XFlies s.r.l, University of Basilicata, 85100 Potenza, Italy \\ * Correspondence: maria.monti@unina.it (M.M.); caruso@unitus.it (C.C.) \\ + These authors contributed equally to this work.
}

check for

updates

Citation: Bertini, L.; Cozzolino, F.; Proietti, S.; Falconieri, G.S.; Iacobucci, I.; Salvia, R.; Falabella, P.; Monti, M.; Caruso, C. What Antarctic Plants Can Tell Us about Climate Changes: Temperature as a Driver for Metabolic Reprogramming. Biomolecules 2021, 11, 1094. https://doi.org/10.3390/ biom11081094

Academic Editor: Giovanna Serino

Received: 8 July 2021

Accepted: 19 July 2021

Published: 23 July 2021

Publisher's Note: MDPI stays neutral with regard to jurisdictional claims in published maps and institutional affiliations.

Copyright: (c) 2021 by the authors. Licensee MDPI, Basel, Switzerland. This article is an open access article distributed under the terms and conditions of the Creative Commons Attribution (CC BY) license (https:// creativecommons.org/licenses/by/ $4.0 /)$.

\begin{abstract}
Global warming is strongly affecting the maritime Antarctica climate and the consequent melting of perennial snow and ice covers resulted in increased colonization by plants. Colobanthus quitensis is a vascular plant highly adapted to the harsh environmental conditions of Antarctic Peninsula and understanding how the plant is responding to global warming is a new challenging target for modern cell physiology. To this aim, we performed differential proteomic analysis on C. quitensis plants grown in natural conditions compared to plants grown for one year inside open top chambers (OTCs) which determine an increase of about $4{ }^{\circ} \mathrm{C}$ at midday, mimicking the effect of global warming. A thorough analysis of the up- and downregulated proteins highlighted an extensive metabolism reprogramming leading to enhanced photoprotection and oxidative stress control as well as reduced content of cell wall components. Overall, OTCs growth seems to be advantageous for C. quitensis plants which could benefit from a better $\mathrm{CO}_{2}$ diffusion into the mesophyll and a reduced ROS-mediated photodamage.
\end{abstract}

Keywords: Colobanthus quitensis; differential proteomic analysis; open top chambers; response to stress; temperature changes

\section{Introduction}

Antarctica is one of the last pristine environments where endemic organisms have progressively specialized to deal with very harsh weather conditions, living often at their physiological limit. This specialization makes them extremely susceptible to any minimal environmental change that could be responsible for the extinction of some species. The Antarctic Peninsula is one of the areas on Earth mostly affected by global warming which is inducing a temperature rise at an alarming rate. In the past 50 years, the mean annual temperature has risen by approximately $2.6^{\circ} \mathrm{C}$ and the mean summer air temperature by $1.5^{\circ} \mathrm{C}$ along the west coast of the Antarctic Peninsula [1,2]. This makes maritime Antarctic an open-air laboratory where the study of the genetic and molecular traits which drive the adaptation of living organisms to rapidly changing environmental conditions may permit the disclosure of molecular biomarkers for efficient climate change monitoring. The climatic conditions of this ecosystem allowed the colonization and survival of only two endemic vascular plants: the pearlwort Colobanthus quitensis (Kunth) Bartl. (Caryophyllaceae) and the hairgrass Deschampsia antarctica Desv. (Poaceae) [3]. Both of them display many morphological and physiological traits related to resistance against constantly low 
temperatures and other environmental stressors such as drought, low nutrient availability, and high irradiance. In particular, Antarctic plants exhibit anatomical adaptations typical of xerophytes such as small and thick leaves and lignified cell walls, associated with thick and tight leaf mesophyll which limits $\mathrm{CO}_{2}$ conductance [4]. Moreover, they evolved many other physiological adaptations such as freezing tolerance, ability to maintain positive photosynthetic rate near $0{ }^{\circ} \mathrm{C}$, resistance to photoinhibitory conditions, and tolerance to water stress ([5] and references therein). Furthermore, a large number of studies are focusing on the role of biotic interactions in plant adaptation and fitness, exploring the leaf-associated microbiota [6-8]. The registered warmer temperature allowed spreading of both plant species due to longer growing seasons, glacier retreats, and an increase in precipitation and plant nutrient availability $[9,10]$. These environmental changes were associated with increased growth and reproduction rates as well as greater production of viable seeds of both species [11]. Moreover, the photosynthetic rate was also positively influenced by small temperature increases, mainly in C. quitensis, improving the vegetative growth [12]. However, it is important to point out that Antarctic plants have developed mechanisms of resistance to low temperatures during millions of years of evolution, and the resilience they have developed in their natural environment could slow down the response to future climate change. On the other hand, warming can reduce plant freezing survival [13] impairing their resistance if the tendency to warm up ceases. Actually, Turner et al. [14] reported that warming in the Antarctic Peninsula stopped during recent decades, even if new warming episodes are likely to occur during this century. Under this natural climate variability, the study of the ecophysiological traits of Antarctic vascular plants that drive their adaptation to cold and warmer growth conditions is a new target for modern plant physiology. Indeed, many papers have recently focused on the analysis of climate influence on anatomical and photosynthetic parameters ([12] and references therein).

Recent developments in "omics" disciplines have opened up new perspectives towards a comprehensive understanding of biological processes related to plant stress responses. In particular, proteomics offers a snapshot of cell metabolism taking into account only the functional molecules that actively contribute to plant cell viability. In a recent work, Clemente-Moreno and colleagues [15] combined metabolomics, ecophysiology, biochemistry, and statistical modeling approaches to understand the mechanisms leading to low temperature tolerance in two $C$. quitensis ecotypes revealing that besides anatomical structures, long-term stress tolerance mechanisms in C. quitensis seem to be sustained by sulfur-based molecules, polyamines, and secondary metabolites.

In order to deepen knowledge on the mechanisms underlying C. quitensis adaptation to climate change, we performed the de novo assembly of $C$. quitensis transcriptome of plants grown in natural condition (OUT samples) versus plants grown for one year inside small greenhouses open on the top, namely open top chambers (OTC samples), which determine an increase of about $4{ }^{\circ} \mathrm{C}$ during midday, mimicking the effect of global warming [16]. Indeed, OTCs are widely recognized as a useful tool for simulating a warmer climate and studying the response of high-latitude ecosystems to warming [17-19].

In this work, we extended the information previously obtained through transcriptomic investigations by adopting a differential proteomic approach. Analyses were performed on OTC versus OUT samples in order to provide a global view of proteome reprogramming triggered by different growth conditions. To combine transcriptomic and proteomic data we built a custom home-made $C$. quitensis protein database reporting the six possible putative protein sequences of each $C$. quitensis transcript. This approach is now widely used because it allows the reliable identification of really expressed proteins. Furthermore, this approach is particularly useful for the identification of proteins from organisms whose sequences are not available in public databases. The proteome profiling has been analyzed in-depth by using a combination of high throughput profiling techniques and bioinformatics tools. Moreover, gene ontology (GO) analysis has been carried out to obtain more comprehensive insight into the biological processes affected by temperature. Interestingly, we found that plants grown at warmer temperature are more protected from photooxidative damage, 
thus suffering less from photoinhibition. Moreover, proteins supporting photorespiration efficiency were found over-expressed, suggesting that RUBISCO oxygenase activity could prevent photoinhibition by reducing ROS-mediated photodamage. Moreover, redox homeostasis appeared to be also supported by the over-expression of some antioxidant enzymes and temperature-induced proteins known to be involved in maintaining the redox state. As for the metabolic processes, higher growth temperatures were found to reduce the synthesis of complex carbohydrates and proteins, being cellular catabolic processes generally upregulated.

\section{Materials and Methods}

\subsection{Sample Collection}

Field activity was carried out in close proximity of the Henryk Arctowski Antarctic Research station, King George Island, Maritime Antarctica $\left(62^{\circ} 14^{\prime} \mathrm{S}, 58^{\circ} 48^{\prime} \mathrm{W}\right)$. Samples were collected inside the Antarctic Specially Protected Area (ASPA) 128 using permits provided by The Chilean Antarctic Institute (INACH) and by the Italian National Agency for New Technologies, Energy and Sustainable Economic Development-Technical Antarctic Unit (ENEA-UTA). Colobanthus quitensis plants were grown in the field inside OTC from December 2012 to March 2014. The OTC were similar to those used in the International Tundra Experiment (ITEX) and, in particular, they were made with transparent Plexiglass ${ }^{\circledR}$ walls of $40 \mathrm{~cm}$ height, punched with 25 holes of $1.5 \mathrm{~cm}$ diameter each to allow some wind to pass through. Temperature sensors inside OTC revealed an average increase of $4{ }^{\circ} \mathrm{C}$ in the internal air temperature during midday [13]. Other parameters, such as mean PAR and relative humidity, were not altered by OTC [12]. Control plots were selected approximately 2-5 m away from each OTC, in random direction. Leaf samples from individuals grown either inside OTC (OTC samples) or in natural conditions (OUT samples) were harvested and pooled. Freshly collected leaves were soaked in $\operatorname{RNAlater}^{\circledR}$ solution $(2: 10, w / v)$ (Sigma-Aldrich, Saint Louis, MO, USA) to preserve RNA and proteins from degradation, and stored at $-20^{\circ} \mathrm{C}$ during Antarctic stay. The samples were first moved to Chile and then to Italy maintaining the cold chain. Once in Italy, they were stored at $-80^{\circ} \mathrm{C}$ until RNA and protein extraction.

\subsection{Colobanthus Quitensis Protein Database Building}

The previously assembled and annotated Colobanthus quitensis transcriptome [16] was used to generate a custom-made protein database. Starting from the 165,508 contigs obtained from the transcriptomic analysis, the six reading frames were translated in their corresponding amino acid sequences by SEQtools software (http:/ /www.seqtools.dk/, accessed on 15 December 2017), thus obtaining 993,048 predicted amino acid sequences ("C. quitensis protein database"). This database provides useful information for proteins identification allowing the combination of transcriptomic and proteomic data, as described in Results and Discussion section.

\subsection{Protein Extraction for Proteomic Analysis}

Two biological replicates for both OTC and OUT samples were finely ground using a mortar and pestle under continuous addition of liquid nitrogen and then a protein extraction buffer (4\% SDS, $20 \mathrm{mM}$ Tris- $\mathrm{HCl} \mathrm{pH} \mathrm{8.0,} 1 \mathrm{mM}$ phenylmethylsulfonyl fluoride (PMSF), protease inhibitor cocktail) was added. Approximately $300 \mu \mathrm{L}$ of buffer was added to each sample, and afterwards incubated for $30 \mathrm{~min}$ at $4{ }^{\circ} \mathrm{C}$ on a stirring wheel and then centrifuged at 13,000 rpm for $30 \mathrm{~min}$. After centrifugation, supernatants containing the protein fraction were collected and protein concentration was determined by the Bradford assay (Bio-rad, Hercules, CA, USA) [20].

\subsection{SDS-PAGE and Mass Spectrometry Analysis}

Fifty micrograms of protein extracts from two biological replicates of both OTC and OUT samples were diluted in Laemmli buffer [21] containing $100 \mathrm{mM}$ dithiothreitol 
(DTT), boiled for $10 \mathrm{~min}$, and loaded onto a 10\% bis-acrylamide gel. After SDS-PAGE separation, the gel was stained with Coomassie Brilliant Blue, and 19 slices were cut from each lane. Each slice was subjected to in situ digestion as previously reported [22]. Finally, the obtained peptide mixtures were collected, vacuum-dried, and then resuspended in $0.2 \%$ formic acid for LC-MS/MS analyses. LC-MS/MS analyses were carried out onto an LTQ Orbitrap XL (ThermoScientific, Waltham, MA, USA) coupled with a nanoLC system (nanoEasy II). Peptide mixtures were separated onto a C18 capillary column (200 mm, $75 \mu \mathrm{m}$ ID, $5 \mu \mathrm{m}, 120 \AA$, Nanoseparation, NL) by using a linear gradient of eluent B ( $0.2 \%$ formic acid in 95\% acetonitrile LC-MS Grade) from 5\% to 95\% in $87 \mathrm{~min}$ at a flow rate of $250 \mathrm{~nL} / \mathrm{min}$. The mass spectrometry analyses were performed using the data-dependent acquisition (DDA) mode: From each MS scan in the range from 400 to $1800 \mathrm{~m} / \mathrm{z}$, the ten most abundant ions were selected and fragmented in collision-induced dissociation (CID) conditions, applying a dynamic exclusion window of $40 \mathrm{~s}$. Each sample was run in duplicates.

\subsection{Protein Identification and Quantification and Statistical Analyses}

LC-MS/MS raw data were processed by MaxQuant 1.5.2 integrated with Andromeda search engine, and the customized "Colobanthus quitensis protein database" was used for protein identification. The parameters employed for protein identification were: minimum 4 peptides, at least 2 unique; methionine oxidation and pyroglutamate formation on $\mathrm{N}$ terminal glutamine as variable modifications; 20 ppm was the accuracy for the first search, then lowered to $4.5 \mathrm{ppm}$ in the main search; and 0.01 FDR with a reverse database for decoy was used. Protein quantification was carried out for proteins showing minimum 2 unique and razor peptides identified. The only modification allowed for quantification was the carbamidomethylation of Cys residues. Protein relative quantification was obtained by using a spectral counts (SpCs) based method. In details, SpCs from MaxQuant were normalized by using RSC method [23], and the means were calculated for technical duplicates. The obtained values were introduced in MultiExperiment Viewer $(\mathrm{MeV})$, performing the unpaired Student's $t$-test imposing a cutoff $p$-value $<0.01$ for the statistical significance. The protein normalized spectral counts in both conditions (OTC and OUT) were used to calculate the fold change (FC) as $\log _{2}$ OTC/OUT. The volcano plot was computed by VolcaNoseR [24] with cutoff values spanning from -0.5 to 0.4 for $\log _{2} \mathrm{FC}$ and 2 for $-\log _{10} p$-value.

\subsection{Bioinformatic Analysis}

Gene ontology (GO) enrichment analysis was conducted using singular enrichment analysis (SEA) in AgriGO toolkit version 1.2 (http:/ / bioinfo.cau.edu.cn/agriGO/analysis. php, accessed on 15 May 2019) [25]. The Arabidopsis Information Resource (TAIR) code of the orthologous Arabidopsis thaliana proteins was used as input and the TAIR10 genome assembly as background. Statistical analysis included Fisher's test and the Yekutieli multiple-test with a threshold of FDR $=0.05$.

Protein-protein interaction (PPI) networks were analyzed using the STRING program version 11.0 (http:/ / string-db.org/, accessed on 3 June 2019) [26] which predicts PPI employing a mixture of prediction approaches and a combination of experimental data (neighborhood, gene fusion, co-expression, experiments, databases, text mining, co-occurrence). Networks were performed at 0.7 confidence level.

\subsection{Enzymatic Activity Assays}

One gram of $C$. quitensis leaves (fresh weight) was finely ground with a mortar and pestle under continuous addition of liquid nitrogen. The powder was resuspended in $5 \mathrm{~mL}$ of $50 \mathrm{mM}$ of cold sodium phosphate buffer ( $\mathrm{pH} 7.6)$ containing $1 \mathrm{mM}$ EDTA, 4\% (w/v) polyvinylpyrrolidone, $3 \mathrm{mM}$ DTT, and a cocktail of protease inhibitors (Complete ULTRA tablets, Roche). After centrifugation at $9000 \mathrm{rpm}$ for $15 \mathrm{~min}$ at $4{ }^{\circ} \mathrm{C}$, the protein content was evaluated according to the method described by Bradford [20] and the supernatant was used for enzyme activity assays as already described [27] with minimal changes. Briefly, 
catalase (CAT) activity was measured monitoring the absorbance decrease at $240 \mathrm{~nm}$ caused by the decomposition of hydrogen peroxide $\left(\varepsilon=0.0436 \mathrm{mM}^{-1} \mathrm{~cm}^{-1}\right)$. The reaction mixture contained $19 \mathrm{mM}$ of $\mathrm{H}_{2} \mathrm{O}_{2}$ in $50 \mathrm{mM}$ of potassium phosphate buffer ( $\mathrm{pH}$ 7.6). Ascorbate peroxidase (APX) activity was assayed by estimating the absorbance decrease at $290 \mathrm{~nm}$ due to the ascorbate oxidation $\left(\varepsilon=2.8 \mathrm{mM}^{-1} \mathrm{~cm}^{-1}\right)$. The reaction mixture contained $0.1 \mathrm{mM}$ of $\mathrm{H}_{2} \mathrm{O}_{2}, 0.5 \mathrm{mM}$ of ascorbate, and $0.1 \mathrm{mM}$ of EDTA in $50 \mathrm{mM}$ of potassium phosphate buffer ( $\mathrm{pH}$ 7.6). Guaiacol peroxidase (POD) activity was measured monitoring the absorbance increase at $470 \mathrm{~nm}$ caused by the reduction of guaiacol to form tetraguaiacol $\left(\varepsilon=26.6 \mathrm{mM}^{-1} \mathrm{~cm}^{-1}\right)$. The reaction mixture contained $0.4 \%$ guaiacol $(v / v)$ and $0.03 \% \mathrm{H}_{2} \mathrm{O}_{2}$ in $100 \mathrm{mM}$ potassium phosphate buffer ( $\mathrm{pH}$ 7.6). Glutathione-S transferase (GST) activity was determined by measuring the absorbance increase at $340 \mathrm{~nm}$ caused by the conjugation of 1-chloro-2,4-dinitrobenzene (CDNB) $\left(\varepsilon=9.6 \mathrm{mM}^{-1} \mathrm{~cm}^{-1}\right)$ with reduced glutathione (GSH). The reaction mixture contained $1 \mathrm{mM}$ of CDNB, $1 \mathrm{mM}$ of GSH in $100 \mathrm{mM}$ of potassium phosphate buffer ( $\mathrm{pH}$ 6.5) containing $1 \mathrm{mM}$ of EDTA. All the above enzyme activities were expressed as unit $\mathrm{mg}^{-1}$ protein. Superoxide dismutase (SOD) activity was assayed using the SOD determination kit (Sigma-Aldrich, Uppsala, Sweden) following the manufacturer's instructions. The kit is based on the use of Dojindo's highly watersoluble tetrazolium salt, WST-1 (2-(4-iodophenyl)-3-(4-nitrophenyl)-5-(2,4-disulfophenyl)2H-tetrazolium, monosodium salt), which produces a water-soluble formazan dye upon reduction by a superoxide anion with a maximum of absorbance at $440 \mathrm{~nm}$. The rate of the reduction is linearly related to the xanthine oxidase activity which generates the superoxide anion, and is inhibited by SOD. Thus, the SOD activity is quantified as an inhibition activity $\left(\mathrm{IC}_{50}\right)$ by measuring the decrease of absorbance at $440 \mathrm{~nm}$.

\subsection{Thiobarbituric Acid Reactive Substance Measurement}

The level of thiobarbituric acid reactive substances (TBARS) was measured to assess lipid peroxidation following the protocol already described [27]. Briefly, $400 \mathrm{mg}$ of C. quitensis leaves (fresh weight) were finely ground using a mortar and pestle under continuous addition of liquid nitrogen. The powder was resuspended in $3 \mathrm{~mL}$ of trichloroacetic acid (TCA) $0.1 \%$ and mixed on the vortex. Following centrifugation at 13,500 rpm for $10 \mathrm{~min}$, $400 \mu \mathrm{L}$ of the supernatant (or $400 \mu \mathrm{L}$ of $0.1 \%$ TCA for the blank) were added either to $1 \mathrm{~mL}$ of $0.5 \%$ TBA in $20 \%$ trichloroacetic acid (+TBA solution) or to $1 \mathrm{~mL}$ of $20 \%$ trichloroacetic acid (-TBA solution) (dilution factor 1:3.5). Samples were incubated at $80{ }^{\circ} \mathrm{C}$ for $30 \mathrm{~min}$ and then cooled on ice. After centrifugation at 13,500 rpm for $5 \mathrm{~min}$, the absorbance was measured both at $532 \mathrm{~nm}$, which represents the maximum absorbance of the TBA-TBARS complex, and $600 \mathrm{~nm}$ to allow correction for nonspecific turbidity. To calculate the TBARS equivalent ( $\mathrm{nmol} \mathrm{mL}{ }^{-1}$ ), the $\varepsilon_{\mu \mathrm{M}}$ of malondialdehyde (MDA), one of the main products of membrane damage, was used according to the following formula:

$$
\left[\mathrm{A} / \varepsilon_{\mu \mathrm{M}} \operatorname{MDA}\left(0.155 \mu \mathrm{M}^{-1} \mathrm{~cm}^{-1}\right)\right] \times \text { dilution factor }
$$

where $A=\left[\left(A_{532 n m(+T B A)}-A_{600 n m(+T B A)}\right)-\left(A_{532 n m(-T B A)}-A_{600 n m(-T B A)}\right)\right]$

\subsection{RNA Extraction and Quantitative Reverse Transcriptase-PCR Analysis}

Total RNA was extracted using the Nucleospin ${ }^{\circledR}$ RNAPlant kit (Macherey-Nagel, Düren, Germany), starting from $100 \mathrm{mg}$ of finely ground leaf samples, in accordance with the manufacturer's instructions. RNA concentration was estimated by reading spectrophotometric absorbance at $260 \mathrm{~nm}$, whereas the $\mathrm{OD}_{260} / \mathrm{OD}_{280}$ and $\mathrm{OD}_{260} / \mathrm{OD}_{230} \mathrm{~nm}$ absorption ratios were calculated to evaluate RNA quality and purity (spectrophotometer UV-30 SCAN, ONDA). RNA integrity was also verified by agarose gel electrophoresis, whereas the absence of DNA contamination was tested using 100 ng of total RNA as a template in a PCR reaction using EF1 $\alpha$ specific primers for amplification. Complementary DNA (cDNA) was synthesized using the ImProm-II ${ }^{\mathrm{TM}}$ reverse transcription system (Promega, Madison, WI, USA) starting from $1 \mu \mathrm{g}$ of RNA as template and using the oligo-dT primer for first strand synthesis. 
Sequence information of the genes to be amplified were obtained from the shotgun transcriptome assembly of C. quitensis leaves (National Center of Biotechnology Information (NCBI) Sequence Read Archive (SRA), accession SRX814890) [16]. For primer pairs design, we searched for all the contigs coding for each of the selected genes inside the transcriptome data and we aligned them using the freely available ClustalW bioinformatics tool (https: / / embnet.vital-it.ch/software/ClustalW.html, accessed on 21 March 2016). Then, primers were designed inside the most conserved region using Primer3 software (http://bioinfo.ut. ee/primer3-0.4.0/, accessed on 28 March 2016). The specificity of each selected primer pair was observed via standard PCR on synthesized CDNA using the BIOTAQ DNA polymerase (Bioline, London, UK), and each amplification product was verified by $1.5 \%$ agarose gel electrophoresis. All primers used in the present study are listed in Table S1.

Quantitative reverse transcriptase-PCR (qRT-PCR) reactions were performed in 96-well plates on a Bio-Rad CFX96 real-time PCR thermal cycler (Bio-Rad, Hercules, CA, USA), using the SYBR green detection system. The reaction mixture $(10 \mu \mathrm{L})$ contained $1 \mu \mathrm{L}$ of four-fold diluted cDNA, $5 \mu \mathrm{L}$ of Sso Advanced SYBR Green Supermix (Bio-Rad, Hercules, CA, USA), and a different concentration of each gene specific primer (Table S1). The cycling conditions were the following: initial denaturation step at $95{ }^{\circ} \mathrm{C}$ for $3 \mathrm{~min}$, followed by 44 cycles at $95^{\circ} \mathrm{C}$ for $10 \mathrm{~s}$, and primer specific annealing temperature for $30 \mathrm{~s}$ (Table S1). Following amplification, the melting curves ranging from 70 to $95^{\circ} \mathrm{C}$ (with a constant increase of $0.5^{\circ} \mathrm{C}$ every $5 \mathrm{~s}$ ) were evaluated in order to check the PCR specificity (Figure S1). Each assay included no-template controls (NTCs) for each primer pair. Primer efficiency $(E)$ was calculated by generating standard curves for each oligonucleotide pair with at least five serial fourfold dilution points and the slope of the amplification curve was used to calculate $E=10^{(-1 / \text { slope })}$. The gene expression of selected protein-coding genes was normalized against the reference genes glucose 6-phosphate dehydrogenase (G6PDH) and catalytic subunit of protein phosphatase $2 \mathrm{~A}(P P 2 A c s)$, as suggested in [28]. The relative gene expression was determined using the $2^{-\Delta \Delta \mathrm{Ct}}$ method. Output data were processed using the CFX Manager ${ }^{\mathrm{TM}}$ Software (Bio-Rad, Hercules, CA, USA). All qRT-PCR reactions were run in three technical and biological replicates.

\subsection{Data Analyses}

For enzymatic activity assays and qRT-PCR analysis the differences between the two growth conditions were compared applying the Student's $t$-test.

Results were expressed as means \pm standard deviation (SD) of three biological and three technical replicates and $p<0.05$ was considered as statistically significant.

\section{Results and Discussion}

Global warming is one of the major threats all over the world and the Antarctic Peninsula is mainly affected by this stressor. The temperature rise influences the life of endemic organisms and the study of its effect on proteome reprogramming of local plants may open up new perspectives on their adaptation to environmental changes. In this work, a differential proteomic analysis was carried out between $C$. quitensis plants grown in natural conditions (OUT samples) and inside open top chambers (OTC samples) which allow plants to live at slightly warmer temperature, mimicking the effect of global warming. An overview of the experimental proteomic workflow is shown in Figure 1. 


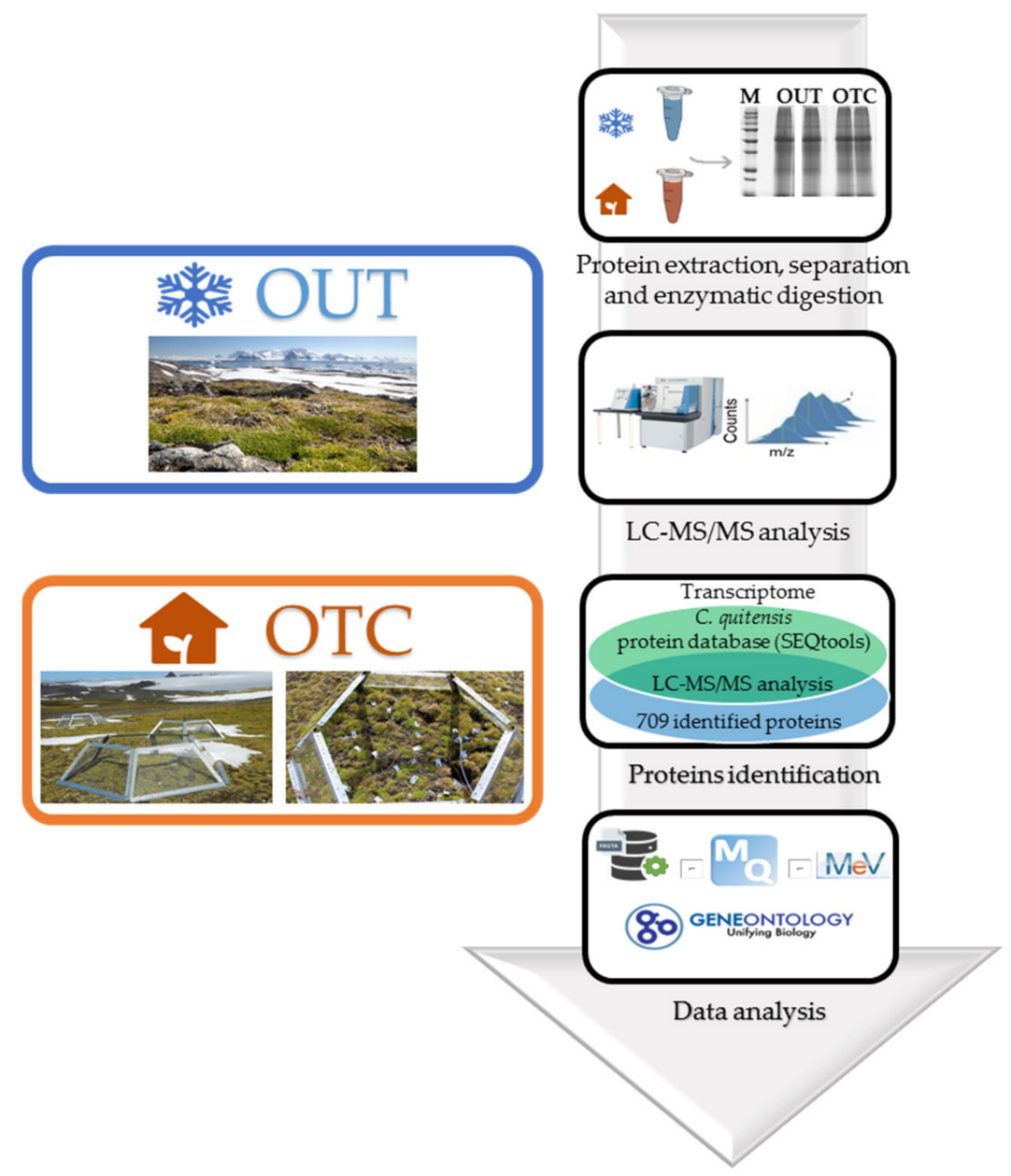

Figure 1. Experimental workflow. The open top chambers used in the experiment are shown.

\subsection{De Novo Colobanthus Quitensis Protein Database Building}

The integrated transcriptomic and proteomic approach is the most reliable and widely used strategy [29-31] for the identification of actually expressed proteins, especially with respect to strategies based exclusively on transcriptomic analyses that allow only the identification of putative proteins without verifying their real expression within the cells. Furthermore, the integrated approach is useful for the identification of proteins in species whose genome/transcriptome is not yet annotated and characterized, so there are no sequences available on public databases. This approach relies on a custom-made putative protein database obtained by the translation of the six reading frames of each transcriptome sequence that becomes the template for the identification of proteins using experimental data derived from the proteomic analysis. In this work we built the C. quitensis protein database using the SEQtools software, thus obtaining a total of 993,048 predicted amino acid sequences. The peptide sequences obtained by nanoLC-MS/MS were compared with the putative amino acid sequences of the C. quitensis protein database allowing to identify with certainty the proteins really expressed.

\subsection{Proteomic and Functional Enrichment Analysis}

The effects at proteomic level of the C. quitensis growth inside OTC were explored in comparison to the natural growth conditions (control) by using a label free differential proteomic approach. Equal amounts of protein extracts from two biological replicates of $C$. quitensis leaves sampled inside and outside OTC were fractionated by SDS-PAGE and the 19 slices cut from each lane were in situ hydrolyzed by trypsin. Peptide mixtures for each condition were analyzed in duplicate by nanoLC-MS/MS. MSMS raw data were employed for protein identification and quantification as described in the methods section, by using 
MaxQuant search engine. A total of 709 proteins (excluding the 25 contaminants) were identified by employing the in-house built Colobanthus quitensis protein database (Table S2). This number was largely higher in comparison to the number of entries (533 excluding the 25 contaminants) obtained from a preliminary search analysis carried out by using the same raw data and search parameters for protein identification within the generalist Viridiplantae database (Table S3). This remarkable finding highlights the importance of using specific protein sequence databases for a more complete and reliable characterization of every peculiar organism. This transcriptomic-proteomic integrated approach allowed for the first time a complete molecular description of $C$. quitensis adaptation to very extreme climatic conditions. The variations of protein expression profiles were evaluated by measuring the number of spectral counts applying RSc method for their normalization and the mean between the technical replicates was calculated. Statistical analysis disclosed 93 significantly differentially expressed proteins $(p<0.01)$. By considering a $\log _{2}$ fold change cutoff between -0.3 and $0.4,41$ proteins resulted upregulated and 52 downregulated in the OTC-grown plants in comparison to the control (Figure 2).

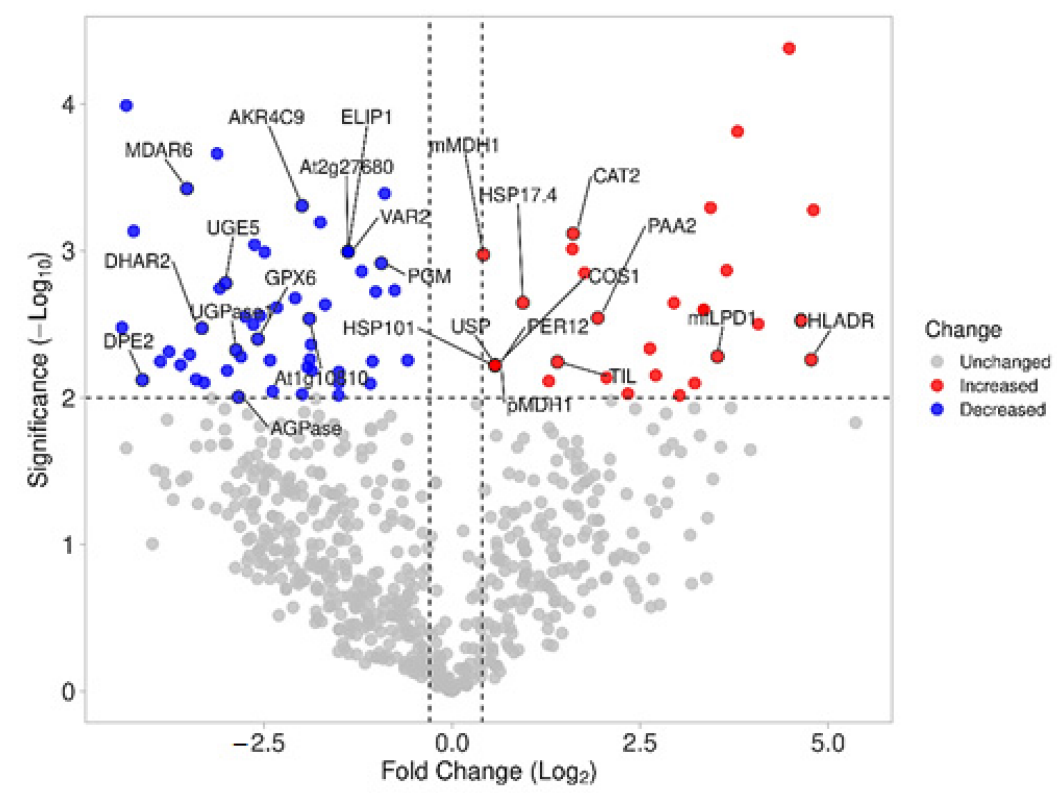

Figure 2. The volcano plot representation of total identified proteins in OTC and OUT samples. In red and blue are reported the statistically significant ( $p$-value $<0.01)$ up- $\left(\log _{2} \mathrm{FC}>0.4\right)$ and downregulated $\left(\log _{2} \mathrm{FC}<-0.5\right)$ proteins, respectively. In gray are reported the non-significant proteins ( $p$-value $\geq 0.01$ and / or $-0.5 \leq \log _{2} \mathrm{FC} \leq 0.4$ ). The gene names of $A$. thaliana orthologs are reported for the representative proteins of the pathways discussed.

The list of differentially expressed proteins (DEPs) is shown in Tables 1 and 2 (the complete mass spectrometry data for each protein are reported in Table S4). The Arabidopsis Information Resource (TAIR) code and description, the $p$-value, and the $\log _{2}$ of the fold change (FC) calculated as the RSc ratio of OTC vs. OUT samples are reported for each protein. In few cases, sequences that code for different proteins hold the same TAIR description as well as sequences with the same TAIR code and TAIR description code for different isoforms (i.e., AT5G44120). 
Table 1. List of the 41 upregulated proteins.

\begin{tabular}{|c|c|c|c|}
\hline TAIR Code & TAIR Description & $p$-Value & $\begin{array}{l}\log _{2} \text { FC } \\
\text { OTC/OUT }\end{array}$ \\
\hline AT2G28490 & RmlC-like cupins superfamily protein & $5.29 \times 10^{-4}$ & 4.81 \\
\hline AT1G54870 & NAD(P)-binding Rossmann-fold superfamily protein & $5.49 \times 10^{-3}$ & 4.78 \\
\hline AT5G60160 & Zn-dependent exopeptidases superfamily protein & $2.95 \times 10^{-3}$ & 4.64 \\
\hline AT5G44120 & ATCRA1, CRA1, CRU1, RmlC-like cupins superfamily protein & $4.18 \times 10^{-5}$ & 4.48 \\
\hline AT5G44120 & ATCRA1, CRA1, CRU1, RmlC-like cupins superfamily protein & $3.14 \times 10^{-3}$ & 4.07 \\
\hline AT3G54470 & Uridine 5'-monophosphate synthase/UMP synthase (PYRE-F) (UMPS) & $1.54 \times 10^{-4}$ & 3.80 \\
\hline AT3G51640 & Stress response NST1-like protein & $1.36 \times 10^{-3}$ & 3.65 \\
\hline AT1G48030 & mtLPD1, mitochondrial lipoamide dehydrogenase 1 & $5.23 \times 10^{-3}$ & 3.53 \\
\hline AT1G04580 & AAO4, AO4, ATAO-4, ATAO2, aldehyde oxidase 4 & $5.10 \times 10^{-4}$ & 3.44 \\
\hline AT1G79530 & GAPCP-1, glyceraldehyde-3-phosphate dehydrogenase of plastid 1 & $2.51 \times 10^{-3}$ & 3.35 \\
\hline AT2G15220 & Plant basic secretory protein (BSP) family protein & $2.51 \times 10^{-3}$ & 3.35 \\
\hline AT3G22640 & PAP85, cupin family protein & $7.96 \times 10^{-3}$ & 3.23 \\
\hline AT2G24530 & Transcriptional regulator of RNA poIII, SAGA & $9.63 \times 10^{-3}$ & 3.03 \\
\hline AT3G09540 & Pectin lyase-like superfamily protein & $2.25 \times 10^{-3}$ & 2.95 \\
\hline AT1G43670 & Inositol monophosphatase family protein (CYFBP, Fructose-1,6-bisphosphatase, cytosolic) & $7.04 \times 10^{-3}$ & 2.71 \\
\hline AT4G25150 & HAD superfamily, subfamily IIIB acid phosphatase & $4.62 \times 10^{-3}$ & 2.63 \\
\hline AT5G19660 & ATS1P, ATSBT6.1, S1P, SITE-1 protease & $9.39 \times 10^{-3}$ & 2.34 \\
\hline AT1G13750 & Purple acid phosphatases superfamily protein & $7.29 \times 10^{-3}$ & 2.05 \\
\hline AT2G05840 & PAA2, 20S proteasome subunit PAA2 & $2.86 \times 10^{-3}$ & 1.93 \\
\hline AT5G67360 & ARA12, subtilase family protein & $1.42 \times 10^{-3}$ & 1.76 \\
\hline AT4G35090 & CAT2, catalase 2 & $7.64 \times 10^{-4}$ & 1.61 \\
\hline AT2G24200 & Cytosol aminopeptidase family protein (ATLAP1, LAP1, LEUCYL AMINOPEPTIDASE 1) & $9.74 \times 10^{-4}$ & 1.60 \\
\hline AT5G58070 & ATTIL, TIL, temperature-induced lipocalin & $5.70 \times 10^{-3}$ & 1.40 \\
\hline AT1G03090 & $\begin{array}{l}\text { MCCA, methylcrotonyl-CoA carboxylase alpha chain, mitochondrial/3-methylcrotonyl-CoA } \\
\text { carboxylase } 1 \text { (MCCA) }\end{array}$ & $7.70 \times 10^{-3}$ & 1.28 \\
\hline AT1G54050 & HSP20-like chaperones superfamily protein & $2.25 \times 10^{-3}$ & 0.94 \\
\hline AT2G22780 & PMDH1, peroxisomal NAD-malate dehydrogenase 1 & $6.05 \times 10^{-3}$ & 0.57 \\
\hline AT1G31190 & IMPL1, myo-inositol monophosphatase like 1 & $5.98 \times 10^{-3}$ & 0.57 \\
\hline AT1G59730 & ATH7, TH7, thioredoxin H-type 7 & $5.98 \times 10^{-3}$ & 0.57 \\
\hline AT1G71695 & Peroxidase superfamily protein & $5.98 \times 10^{-3}$ & 0.57 \\
\hline AT1G74310 & ATHSP101, HOT1, HSP101, heat shock protein 101 & $5.98 \times 10^{-3}$ & 0.57 \\
\hline AT2G05030 & Transposable element gene & $5.98 \times 10^{-3}$ & 0.57 \\
\hline AT2G05710 & ACO3, aconitase 3 & $5.98 \times 10^{-3}$ & 0.57 \\
\hline AT2G25890 & Oleosin family protein & $5.98 \times 10^{-3}$ & 0.57 \\
\hline AT2G29570 & ATPCNA2, PCNA2, proliferating cell nuclear antigen 2 & $5.98 \times 10^{-3}$ & 0.57 \\
\hline AT2G44050 & $\begin{array}{l}\text { COS1, COS1, 6,7-dimethyl-8-ribityllumazine synthase/DMRL synthase/lumazine } \\
\text { synthase/riboflavin synthase }\end{array}$ & $5.98 \times 10^{-3}$ & 0.57 \\
\hline AT3G01570 & Oleosin family protein & $5.98 \times 10^{-3}$ & 0.57 \\
\hline AT3G11930 & Adenine nucleotide alpha hydrolases-like superfamily protein & $5.98 \times 10^{-3}$ & 0.57 \\
\hline AT3G23490 & CYN, cyanase & $5.98 \times 10^{-3}$ & 0.57 \\
\hline AT3G55620 & emb1624, translation initiation factor IF6 & $5.98 \times 10^{-3}$ & 0.57 \\
\hline AT4G16260 & Glycosyl hydrolase superfamily protein & $5.98 \times 10^{-3}$ & 0.57 \\
\hline AT1G53240 & mMDH1, lactate/malate dehydrogenase family protein & $1.06 \times 10^{-3}$ & 0.41 \\
\hline
\end{tabular}


Table 2. List of the 52 downregulated proteins.

\begin{tabular}{|c|c|c|c|}
\hline TAIR Code & TAIR Description & $p$-Value & $\begin{array}{c}\log _{2} \text { FC } \\
\text { OTC/OUT }\end{array}$ \\
\hline AT5G05200 & Protein kinase superfamily protein & $3.33 \times 10^{-3}$ & -4.39 \\
\hline AT1G77510 & RPT3, regulatory particle triple-A ATPase 3 & $1.03 \times 10^{-4}$ & -4.33 \\
\hline AT5G58290 & RPT3, regulatory particle triple-A ATPase 3 & $7.35 \times 10^{-4}$ & -4.23 \\
\hline AT2G40840 & DPE2, disproportionating enzyme 2 & $7.56 \times 10^{-3}$ & -4.11 \\
\hline AT2G20420 & ATP citrate lyase (ACL) family protein & $5.65 \times 10^{-3}$ & -3.88 \\
\hline AT3G23570 & Alpha/beta-Hydrolases superfamily protein & $4.85 \times 10^{-3}$ & -3.76 \\
\hline AT1G79870 & D-isomer specific 2-hydroxyacid dehydrogenase family protein & $5.97 \times 10^{-3}$ & -3.61 \\
\hline AT1G63940 & MDAR6, monodehydroascorbate reductase 6 & $3.78 \times 10^{-4}$ & -3.52 \\
\hline AT5G17380 & Thiamine pyrophosphate dependent pyruvate decarboxylase family protein & $5.08 \times 10^{-3}$ & -3.49 \\
\hline AT1G11860 & Glycine cleavage T-protein family & $7.50 \times 10^{-3}$ & -3.40 \\
\hline AT1G75270 & DHAR2, dehydroascorbate reductase 2 & $3.35 \times 10^{-3}$ & -3.32 \\
\hline AT5G48540 & Receptor-like protein kinase-related family protein & $7.88 \times 10^{-3}$ & -3.30 \\
\hline AT3G55270 & ATMKP1, MKP1, mitogen-activated protein kinase phosphatase 1 & $2.18 \times 10^{-4}$ & -3.12 \\
\hline AT4G18810 & NAD(P)-binding Rossmann-fold superfamily protein & $1.80 \times 10^{-3}$ & -3.09 \\
\hline AT4G10960 & UGE5, UDP-D-glucose/UDP-D-galactose 4-epimerase 5 & $1.66 \times 10^{-3}$ & -3.01 \\
\hline AT4G11150 & emb2448, TUF, TUFF, VHA-E1, vacuolar ATP synthase subunit E1 & $6.54 \times 10^{-3}$ & -2.99 \\
\hline AT3G03250 & AtUGP1, UGP, UGP1, UDP-GLUCOSE PYROPHOSPHORYLASE 1 & $4.73 \times 10^{-3}$ & -2.87 \\
\hline AT1G74910 & ADP-glucose pyrophosphorylase family protein & $9.88 \times 10^{-3}$ & -2.84 \\
\hline AT1G48830 & Ribosomal protein S7e family protein & $5.25 \times 10^{-3}$ & -2.81 \\
\hline AT1G53450 & Epstein-barr nuclear antigen & $2.81 \times 10^{-3}$ & -2.74 \\
\hline AT1G72680 & ATCAD1, CAD1, cinnamyl-alcohol dehydrogenase & $3.17 \times 10^{-3}$ & -2.64 \\
\hline AT5G26780 & SHM2, serine hydroxymethyltransferase 2 & $9.12 \times 10^{-4}$ & -2.62 \\
\hline AT4G11600 & ATGPX6, GPX6, LSC803, PHGPX, glutathione peroxidase 6 & $3.98 \times 10^{-3}$ & -2.58 \\
\hline AT2G45300 & RNA 3'-terminal phosphate cyclase/enolpyruvate transferase, alpha/beta & $2.76 \times 10^{-3}$ & -2.55 \\
\hline ATCG01280 & YCF2.2, chloroplast Ycf2;ATPase, AAA type, core & $1.03 \times 10^{-3}$ & -2.49 \\
\hline AT1G19920 & $\begin{array}{l}\text { APS2, ASA1, pseudouridine synthase/archaeosine transglycosylase-like } \\
\text { family protein }\end{array}$ & $5.55 \times 10^{-3}$ & -2.42 \\
\hline AT1G09310 & Protein of unknown function, DUF538 & $9.05 \times 10^{-3}$ & -2.39 \\
\hline AT5G46290 & KAS I, KAS1, 3-ketoacyl-acyl carrier protein synthase I & $2.42 \times 10^{-3}$ & -2.33 \\
\hline AT3G53580 & Diaminopimelate epimerase family protein & $2.09 \times 10^{-3}$ & -2.08 \\
\hline AT2G30110 & ATUBA1, MOS5, UBA1, ubiquitin-activating enzyme 1 & $9.46 \times 10^{-3}$ & -1.99 \\
\hline AT2G37770 & $\begin{array}{c}\text { NAD(P)-linked oxidoreductase superfamily protein (AKR4C9, ALDO-KETO } \\
\text { REDUCTASE FAMILY } 4 \text { MEMBER C9, CHLAKR, CHLOROPLASTIC } \\
\text { ALDO-KETO REDUCTASE) }\end{array}$ & $4.95 \times 10^{-4}$ & -1.99 \\
\hline AT5G17770 & ATCBR, CBR, CBR1, NADH:cytochrome B5 reductase 1 & $6.18 \times 10^{-3}$ & -1.92 \\
\hline AT1G10810 & NAD(P)-linked oxidoreductase superfamily protein & $2.89 \times 10^{-3}$ & -1.90 \\
\hline AT1G09130 & ATP-dependent caseinolytic $(\mathrm{Clp})$ protease/crotonase family protein & $5.48 \times 10^{-3}$ & -1.89 \\
\hline AT5G61510 & GroES-like zinc-binding alcohol dehydrogenase family protein & $4.33 \times 10^{-3}$ & -1.87 \\
\hline AT2G42590 & GF14 MU, GRF9, general regulatory factor 9 & $6.54 \times 10^{-3}$ & -1.86 \\
\hline AT3G49830 & P-loop containing nucleoside triphosphate hydrolases superfamily protein & $6.41 \times 10^{-4}$ & -1.75 \\
\hline
\end{tabular}


Table 2. Cont.

\begin{tabular}{|c|c|c|c|}
\hline TAIR Code & TAIR Description & $p$-Value & $\begin{array}{c}\log _{2} \mathrm{FC} \\
\text { OTC/OUT }\end{array}$ \\
\hline AT2G22910 & NAGS1, N-acetyl-1-glutamate synthase 1 & $2.32 \times 10^{-3}$ & -1.69 \\
\hline AT4G17170 & $\begin{array}{c}\text { AT-RAB2, ATRAB-B1B, ATRAB2A, ATRABB1C, RAB-B1B, RAB2A, RABB1C, RAB } \\
\text { GTPase homolog B1C }\end{array}$ & $9.62 \times 10^{-3}$ & -1.51 \\
\hline AT2G22780 & PMDH1, peroxisomal NAD-malate dehydrogenase 1 & $6.68 \times 10^{-3}$ & -1.50 \\
\hline AT3G51800 & ATEBP1, ATG2, EBP1, metallopeptidase M24 family protein & $7.91 \times 10^{-3}$ & -1.50 \\
\hline AT2G27680 & NAD(P)-linked oxidoreductase superfamily protein & $1.01 \times 10^{-3}$ & -1.38 \\
\hline AT2G30950 & FTSH2, VAR2, FtsH extracellular protease family & $1.02 \times 10^{-3}$ & -1.38 \\
\hline AT3G22840 & ELIP, ELIP1, chlorophyll A-B binding family protein & $1.02 \times 10^{-3}$ & -1.38 \\
\hline AT1G62780 & Dimethylallyl, adenosine tRNA methylthiotransferase & $1.38 \times 10^{-3}$ & -1.20 \\
\hline AT4G24280 & cpHsc70-1, chloroplast heat shock protein 70-1 & $8.01 \times 10^{-3}$ & -1.09 \\
\hline AT2G21530 & SMAD/FHA domain-containing protein & $5.64 \times 10^{-3}$ & -1.06 \\
\hline AT5G17920 & ATCIMS, ATMETS, ATMS1, cobalamin-independent synthase family protein & $1.89 \times 10^{-3}$ & -1.01 \\
\hline AT1G70730 & Phosphoglucomutase/phosphomannomutase family protein (PGM) & $1.22 \times 10^{-3}$ & -0.94 \\
\hline AT3G04770 & RPSAb, 40s ribosomal protein SA B & $4.08 \times 10^{-4}$ & -0.90 \\
\hline AT4G35090 & CAT2, catalase 2 & $1.85 \times 10^{-3}$ & -0.76 \\
\hline AT1G80380 & P-loop containing nucleoside triphosphate hydrolases superfamily protein & $5.56 \times 10^{-3}$ & -0.59 \\
\hline
\end{tabular}

In order to achieve a fast identification of the biological relevance of DEPs, a gene ontology (GO) functional enrichment analysis was performed by means of the AgriGO toolkit (http:/ / bioinfo.cau.edu.cn/agriGO/analysis.php, accessed on 15 May 2019) [25] using the TAIR code of orthologous Arabidopsis proteins as input. The classification of up- and downregulated DEPs into the biological process, molecular function, and cellular components domains is shown in Figures 3 and 4, respectively. Regarding the upregulated DEPs, the biological process domain was found to be highly enriched in the "metabolic process" (GO:0008152, FDR < 0.05) $(46 \%)$ and "response to stimulus" (GO:0050896, FDR < 0.001) (44\%) terms. In particular, 19/41 upregulated DEPs were disclosed into the "metabolic process" term, which is a broad category comprising multiple molecular activities, whereas 18/41 DEPs were included in the "response to stimulus" term (GO:0050896, FDR < 0.001), encompassing "response to abiotic stimulus", "response to stress", and "response to chemical stimulus" terms (Figure 3).

Among the DEPs related to response to stimulus, we found proteins known to enhance plant tolerance to heat shock and oxidative stress, such as heat shock proteins (namely, HSP101 (AT1G74310) and HSP20-like (HSP17.4, AT1G54050)), temperatureinduced lipocalin (TIL, AT5G58070), adenine nucleotide alpha hydrolases-like superfamily protein (universal stress protein, AT3G11930), catalase (CAT2, AT4G35090), peroxidase (AT1G71695) (Table 1). Interestingly, we also found the upregulation of the suppressor of coronatine insensitive 1 (COS1, AT2G44050) (Table 1), which plays a role in the plant response against biotic stress. Indeed, COS1 impairs Jasmonate-mediated plant response against insect and necrotrophic pathogen attacks [32]. According to this finding, it could be hypothesized that $C$. quitensis grown inside OTCs saves energy by avoiding the activation of wasteful signaling pathways, and at the same time hijacking resources towards defense against abiotic stresses. This hypothesis can be strengthened by the evidence that several DEPs within the biological process term are related to the response to different abiotic stresses and none to biotic stress (Figure 3). Besides the response to stimulus, 5/41 upregulated DEPs (12.5\%) fall into the categories of "cellular catabolic process" (GO:0044248) and the same percentage was found for the "proteolysis" (GO:0006508) term. 
$\begin{array}{lllllllllllllll}0 & 5 & 10 & 15 & 20 & 25 & 30 & 35 & 40 & 45 & 50 & 55 & 60 & 65 & 70\end{array}$

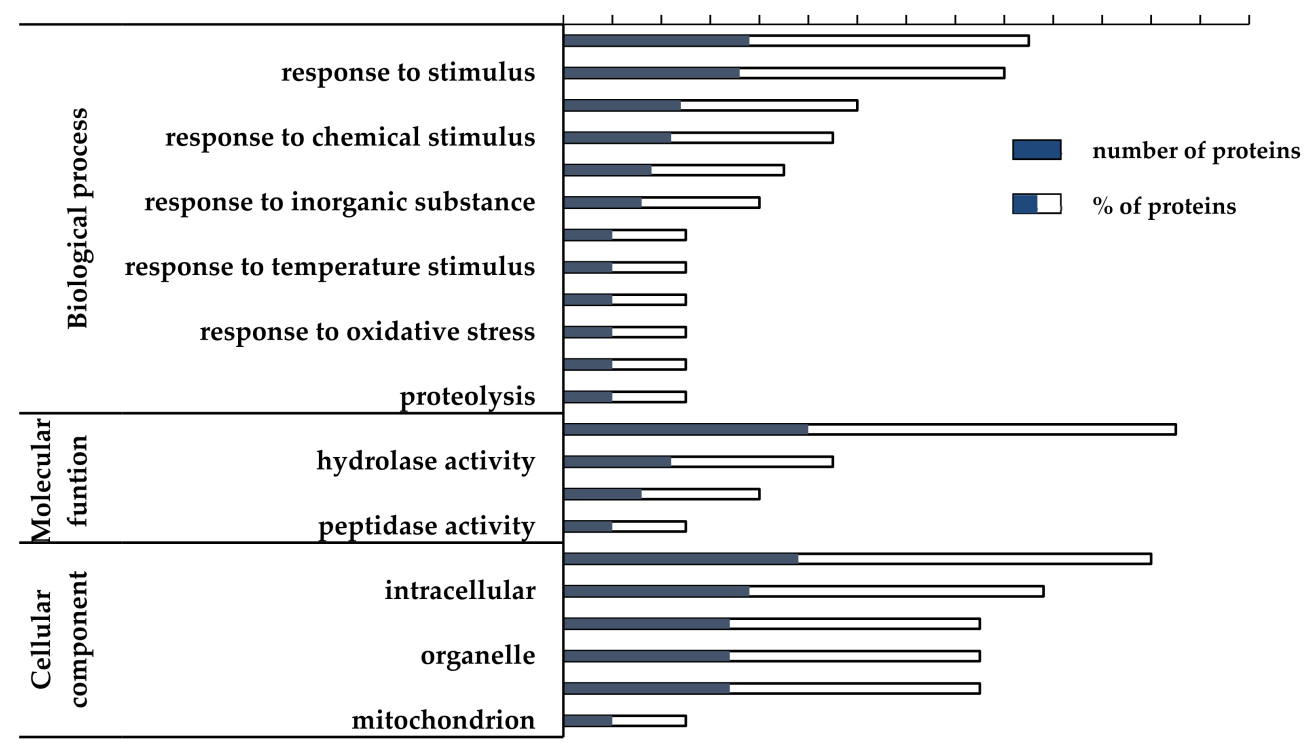

Figure 3. GO functional classification of the upregulated DEPs. The blue bar represents the number of upregulated proteins included in each GO term, whereas the sum of the blue and white bars represents the corresponding protein percentage.

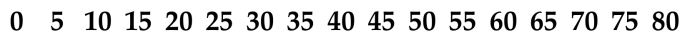

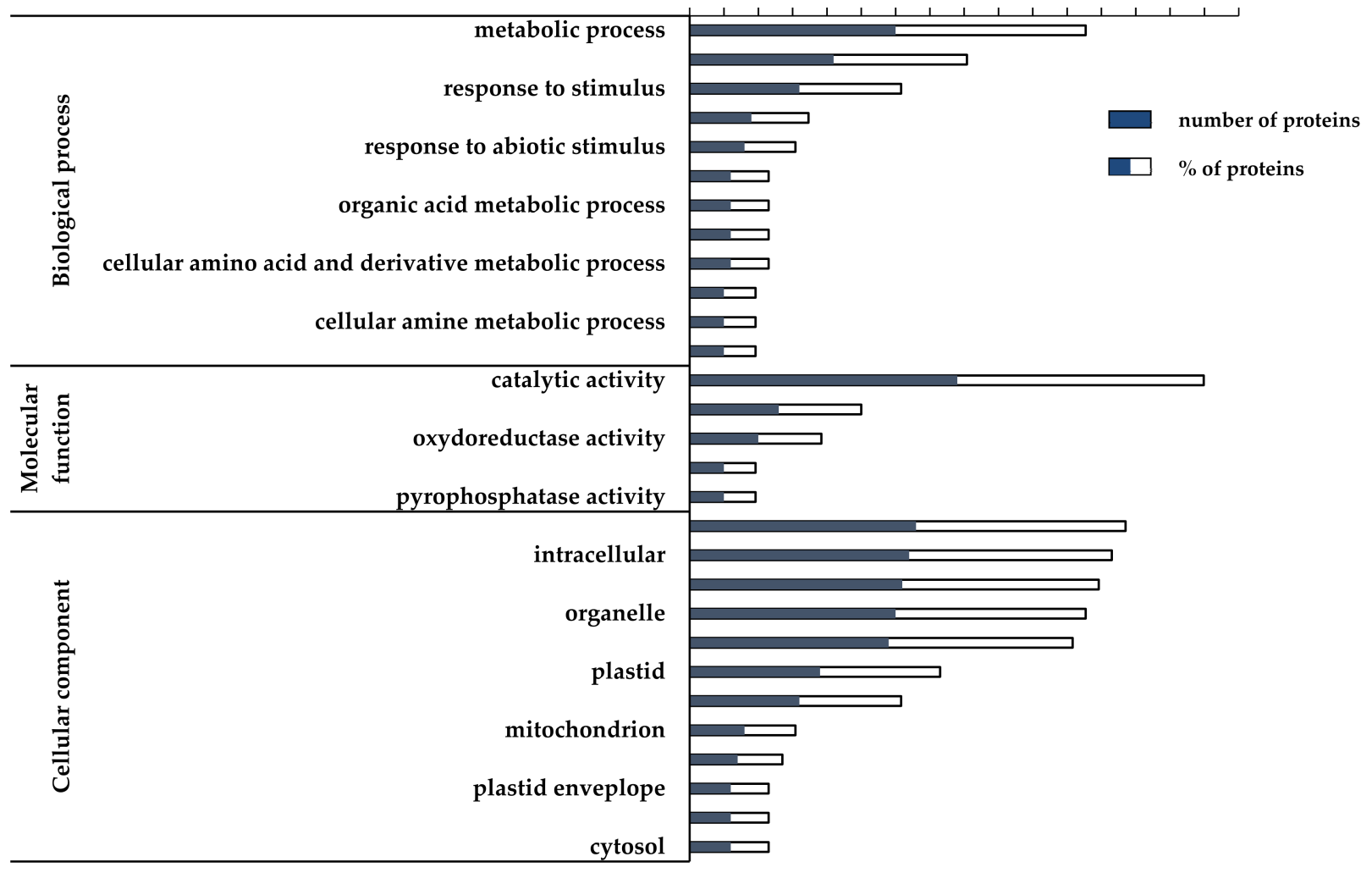

Figure 4. GO functional classification of the downregulated DEPs. The blue bar represents the number of downregulated proteins included in each GO term, whereas the sum of blue and white bars represents the corresponding protein percentage.

As for the downregulated DEPs, 30/52 DEPs (58\%) matched with the "metabolic process term" (GO:0008152, FDR < 0.001) and 16/52 DEPs $(31 \%)$ were included in the "response to stimulus" term (GO:0050896, FDR < 0.01). The last term comprises "response to abiotic stimulus", "response to stress", and "response to cold" (Figure 4). 
Among the latter DEPs, we found two proteins involved in photodamage recovery and photoprotection, respectively variegated 2 (VAR2, AT2G30950) and early lightinducible protein ELIP1 (AT3G22840) (Table 2), whose downregulation indicates that OTC plants are less affected by high irradiation damage than OUT plants. Conversely, this would lead to the hypothesis that photoprotection mechanisms are more efficient in OTC plants. As for the metabolic process term, most of the DEPs belonged to cellular nitrogen compound (GO:0034641) and amine (GO:0009308) metabolic process as well as cellular ketone (GO:0042180) and organic acid metabolic process (GO:0006082). Interestingly, inside these categories we found proteins involved in amino acids and complex carbohydrates biosynthesis.

At first glance, the functional enrichment analysis of up- and downregulated DEPs suggests that there is a general over-expression of proteins involved in the plant response to various abiotic stresses in OTC samples and that these plants rely on more efficient photodamage protection mechanisms. Beside this general achievement, further hypotheses have been made on how growth within OTCs can affect the physiology of $C$. quitensis plant.

\subsection{Photorespiration Protects Photosynthetic Apparatus Counteracting Photooxidation in C. quitensis Plants under Warming Conditions}

C. quitensis plants are highly adapted to the environmental stressors they have to face, so that even a small change in life conditions could have a strong impact on plant physiology if compared to the same change experienced in a less extreme environment [33]. Cold adaptation traits include peculiar foliar anatomy and freezing tolerance mechanisms, as well as the ability to photosynthesize under different irradiance levels and temperatures [34]. Indeed, constitutive leaf anatomical traits involved in tolerance to harsh environmental conditions (e.g., high cell wall thickness) were found to cause low mesophyll conductance whose negative effect was counteracted by the presence of the high- $\mathrm{CO}_{2}$ affinity Rubisco enzyme [4]. Nevertheless, simultaneous episodes of high irradiance and low temperature can cause an energy imbalance and high PSII excitation pressure which promote oxidative stress leading to photoinhibition [35]. It has been widely suggested that photorespiration may play an important role in protecting C3 plants against photooxidation, and abiotic stress in general, thus preventing an excessive production of ROS [36,37]. Indeed, the role of photorespiration has been largely re-evaluated in recent times as a key ancillary component of photosynthesis and therefore of the global carbon cycle [38]. In our atmosphere, one third of the ribulose 1,5-bisphosphate molecules become oxygenated at moderate temperature and even more in a warm environment forcing the respiratory 2-phosphoglycolate recycling that accelerates net carbon assimilation [38]. Moreover, photorespiration can help dissipating the excess of reducing equivalents and energy, thus controlling energy/redox imbalance. Photorespiratory reactions serve as direct sinks for photosynthetically generated ATP, NADPH, and reduced ferredoxin, in order to regenerate acceptors for the primary reactions [39]. Any disturbance of the balance between the supply and demand of ATP/NADPH can lead to the accumulation of ROS and consequent damage of cell components including photodamage of photosystems [40]. In this study, many enzymes supporting the photorespiratory pathway efficiency were found to be over-expressed in plants grown inside OTCs. In particular, differential proteomic analysis revealed the over-expression of both mitochondrial (mMDH1, AT1G53240) and peroxisomal malate dehydrogenase (PMDH1, AT2G22780) in OTC samples $\left(\log _{2} \mathrm{FC}=0.41\right.$ and 0.57, respectively) (Table 1). MDHs are the key enzymes of the malate valves which use malate/oxaloacetate (OAA) shuttles to balance the ATP/NAD(P)H ratio between cellular compartments [41]. Mitochondrial MDH is reported to play an important role in photorespiration, being involved in lowering the concentration of NADH equivalents produced during the oxidation of glycine to serine by the glycine decarboxylase complex (GDC), thus preventing its inhibitory effect on the enzyme activity [42]. Accordingly, a $m m d h 1 m m d h 2$ Arabidopsis mutant, lacking mMDH activity, showed altered photorespiration parameters and higher Gly levels than the wild type, due to the imbalance of glycine decarboxylation reaction. Moreover, it showed an enhanced leaf respiration suggesting 
that $\mathrm{mMDH}$ normally uses NADH to reduce oxaloacetate to malate, rather than to drive mitochondrial respiration [43]. The recovery of $\mathrm{mMDH}$ activity led to suppression of respiratory rate, improvement of photorespiration, and an increase of plant growth, suggesting a role of $\mathrm{mMDH}$ in these processes [43]. The requirement of NADH for hydroxypyruvate reduction in peroxisomes would provide an additional sink for reducing equivalents, and peroxisomal $\mathrm{MDH}$ is involved in the conversion of malate to OAA to guarantee the optimal rate of photorespiration [44]. The over-expression of this enzyme in OTC samples supports the hypothesis that plants grown in warmer conditions display higher photorespiration rates. Interestingly, the mitochondrial dihydrolipoyl dehydrogenase (mtLPD1, AT1G48030) was also found to be strongly over-expressed in OTC samples $\left(\log _{2} \mathrm{FC}=3.53\right)$ (Table 1$)$. Mitochondrial LPD is a crucial component of important metabolic protein complexes, such as pyruvate dehydrogenase, 2-oxoglutarate dehydrogenase, branched-chain 2-oxoacid dehydrogenase, and glycine decarboxylase complexes. Arabidopsis plants over-expressing mtLPD were reported to have increased photorespiration and $\mathrm{CO}_{2}$ assimilation rates as well as enhanced plant growth [45]. In particular, the level of several diagnostic metabolites of TCA cycle and photorespiration were found significantly decreased in the over-expression lines, suggesting that elevated mtLPD activity might facilitate carbon flow through these pathways, thus lowering the accumulation of photorespiratory metabolites which impair both Rubisco and other Calvin-Benson cycle enzymes activity. As a consequence, overexpression lines showed enhanced $\mathrm{CO}_{2}$ fixation and improved light capture and light use efficiency due to a greater availability of $\mathrm{NADP}^{+}$as electron acceptor at PSI [45]. Interestingly, by using the freely available STRING program, both mitochondrial and peroxisomal MDH1 as well as mtLDP1 were predicted to interact each other confirming their involvement in a network of physiological processes strictly connected to $C$. quitensis response to warming (Figure S2A). Thus, we can hypothesize that under warming conditions, mtLPD, together with $\mathrm{mMDH}$ and $\mathrm{PMDH}$, may enhance photorespiration efficiency in C. quitensis, thus controlling the energy/redox balance and stimulating photosynthetic $\mathrm{CO}_{2}$ assimilation with positive effect on plant growth and biomass production. Although photorespiration has often been considered a wasteful pathway associated with reduced carbon gain in $\mathrm{C}_{3}$ plants $[39,46]$, recent studies revealed a positive correlation between photorespiration and yields of some highly productive wheat genotypes [47,48]. In fact, photorespiration is emerging as a crucial component of processes involved in the reduction of ROS production, protection against photoinhibition, optimization of photosynthesis and support for plant growth ([37] and references therein). Moreover, the beneficial role of photorespiration is also related to the release of intermediate molecules which can be hijacked towards other pathways. For example, $\mathrm{H}_{2} \mathrm{O}_{2}$ released during photorespiratory metabolism is probably involved in signal transduction that modulates plant growth and development, as well as abiotic stress responses. In addition, glycine, generated during photorespiration, can be used as a substrate for biosynthesis of glutathione, a key component of antioxidant defense systems, and both glycine and serine can also be withdrawn from the photorespiratory pathway for export $[39,49]$.

\subsection{Warming Conditions Influence High Irradiance-Induced Photodamage in C. quitensis}

It has been reported that $C$. quitensis dissipates the excess of absorbed energy through non-photochemical quenching (NPQ), downregulating its electron transport rate and thereby minimizing oxygen reduction and the generation of reactive oxygen species [50]. Interestingly, cold-acclimated C. quitensis plants were found to recover from cold-induced photoinhibition better and faster than non-acclimated plants implying an intrinsic ability of Antarctic plants to overcome stressors they struggle with [51]. In this study, differential proteomic analysis revealed the under-expression of proteins involved in photoprotection and photodamage recovery, leading to the hypothesis that warming might stimulate metabolic reprogramming which protects plants against photoinhibition. In this context, the enhancement of photorespiration, experienced by C. quitensis plants grown inside OTCs, could play an important role in photoprotection, as reported for many plant species [52-54]. 
In particular, differential proteomic analysis revealed the under-expression of VARIEGATED 2 (VAR2, AT2G30950) protein in OTC samples $\left(\log _{2} \mathrm{FC}=-1.38\right)$ (Table 2). VAR2 is an ATP-dependent metalloprotease belonging to the FtsH (Filamentation temperature sensitive) family, found in eubacteria, animals, and plants [55]. In Arabidopsis thaliana, $\mathrm{M}$ family members are present (FtsH1-12) and their subcellular localization is restricted to mitochondria and chloroplasts [56]. Arabidopsis knock-out mutants of ftsh2 (var2) were found to be highly sensitive to photosystem II (PSII) photodamage [57] and a complex consisting of $\mathrm{FtsH} 2$ and FtsH5 appeared to be involved in the degradation of the PSII reaction center protein D1 which is a key process in the repair cycle of photodamaged PSII [58]. Thus, these findings indicate VAR2 as a key enzyme in plant photoprotection mechanisms. This statement was strengthened by the evidence that its expression was upregulated by high light in Arabidopsis [59] as well as in the unicellular green alga Chlamydomonas reinhardtii [60]. According to VAR2 under-expression, we also found that the gene coding PSII protein D1 ( $p s b A)$ was significantly under-expressed in OTC samples (Figure 5), highlighting a reduced turnover rate of this protein. Interestingly, in this work we also disclosed the under-expression of ELIP1 (early light-inducible protein 1, AT3G22840) in OTC samples ( $\log _{2} \mathrm{FC}=-1.38$ ) (Table 2). ELIPs belong to a class of proteins structurally related to the chlorophyll- and carotenoid-binding light harvesting complexes (LHCs) and accumulate transiently under conditions of high light intensities when the expression of LHC is downregulated [61,62]. This protein family has been hypothesized to play a role in photoprotection either by maintaining a low level of free chlorophyll, thus avoiding ROS formation, or by promoting zeaxanthin-dependent photoprotection $[63,64]$. A green algal homologue of ELIPs (Cbr), upregulated under light stress, was supposed to bind zeaxanthin and have a role in zeaxanthin-associated photoprotection $[65,66]$. According to ELIP1 under-expression, we also found the downregulation of the gene coding the xanthophyll cycle enzyme violaxanthin de-epoxidase (VDE) (Figure 5), which contributes to the dissipation of excess light energy as heat through NPQ mechanism by transforming violaxanthin to zeaxanthin in high light [67]. This result strengthens the hypothesis that $C$. quitensis plants grown under warming conditions could be less exposed to photooxidative damage than the counterpart grown in open field.

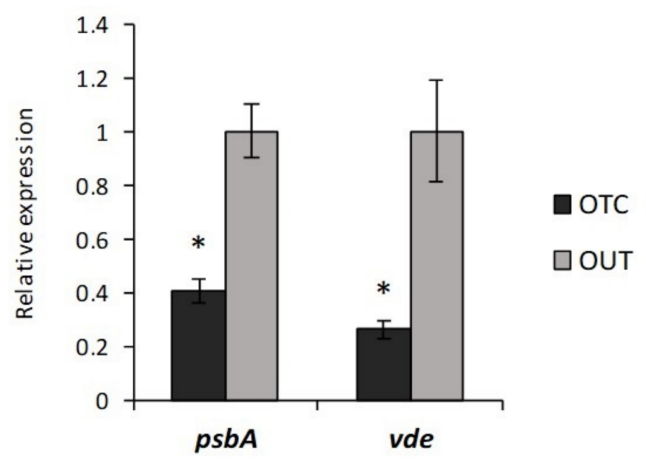

Figure 5. Relative expression of $C$. quitensis genes normalized with G6PDH and PP2Acs genes. psbA: PSII protein D1; vde: violaxanthin de-epoxidase. Data represent the mean \pm SD from three biological and three technical replicates. Asterisks indicate significant differences (Student $t$-test ${ }^{*} p \leq 0.05$ ).

\subsection{Temperature-Induced Lipocalin (TIL) and HSPs Contribute to Oxidative-Stress Control}

Lipocalins are a group of widely distributed proteins that have been found in bacteria, invertebrates, vertebrates and plants [68]. Plants' lipocalins are classified as temperatureinduced lipocalin (TIL) and chloroplastic lipocalin (CHL) [69]. Recently, Boca and colleagues [70] demonstrated overlapping functions between AtCHL and AtTIL in Arabidopsis leaves and the involvement of both lipocalins in oxidative stress tolerance. In particular, AtTIL, as a peripheral membrane protein, was reported to alleviate heat-induced oxidative stress on Arabidopsis membrane limiting the accumulation of lipid peroxidation products [71]. Interestingly, in this work the TIL protein (AT5G58070) was found to be 
over-expressed in OTC samples $\left(\log _{2} \mathrm{FC}=1.4\right)$ (Table 1$)$, thus we assumed its involvement in the oxidative-stress control. Moreover, differential proteomic analysis also revealed the over-expression of some heat shock proteins (HSPs), widely recognized as molecular effectors for oxidative stress protection [72,73]. In particular, HSP101 (AT1G74310), belonging to the Hsp100/ClpB family, and HSP17.4 (AT1G54050), belonging to the HSP20-like family, showed $\log _{2} \mathrm{FC}$ equal to 0.57 and 0.94 , respectively (Table 1 ). HSPs were first identified as strongly induced by heat stress signaling molecules, such as plant hormones and ROS, and are now known to be expressed in response to a wide range of other environmental threats, such as drought, salinity, cold and oxidative stress [72,74]. They function as molecular chaperones contributing to cellular homeostasis under optimal and sub-optimal growth conditions, and play complementary roles in protecting proteins against stress [72]. In particular, their ability to maintain glutathione in its reduced form, even under oxidative conditions, is driving the emerging evidence that these proteins are capable of decreasing the intracellular level of ROS in a glutathione-dependent way, restoring redox homeostasis [73]. Moreover, many other proteins cooperate to control oxidative stress in OTC samples, such as the peroxisomal catalase CAT2 (AT4G35090, $\log _{2} \mathrm{FC}=1.61$ ), the peroxidase PER12 (AT1G71695, $\log _{2} \mathrm{FC}=0.57$ ) and the chloroplast aldehyde reductase ChlADR (NAD(P)-binding Rossmann-fold superfamily protein, AT1G54870, $\log _{2} \mathrm{FC}=4.78$ ) (Table 1 ), which helps maintain the photosynthetic process by detoxifying reactive carbonyls formed during lipid peroxidation. On the other hand, we also found the downregulation of some other aldo-keto reductase isoforms (i.e., NAD(P)-linked oxidoreductase superfamily protein AT1G10810, $\log _{2} \mathrm{FC}=-1.90 ;$ AT2G27680, $\log _{2} \mathrm{FC}=-1.38 ;$ AT2G37770, $\log _{2} \mathrm{FC}=-1.99$ ) (Table 2) leading to the hypothesis that plants drive the expression of specific isoforms depending on the substrate specificity and cellular localization. Moreover, two key enzymes of the ascorbate-glutathione cycle, i.e., the monodehydroascorbate reductase 6, MDAR6 (AT1G63940, $\log _{2} \mathrm{FC}=-3.52$ ) and the dehydroascorbate reductase 2, DHAR2 (AT1G75270, $\log _{2} \mathrm{FC}=-3.32$ ) were found to be downregulated (Table 2). These enzymes are believed to protect plants from oxidative stress by recycling the antioxidant ascorbic acid. Arabidopsis contains six MDAR isoforms, and three DHAR isoforms, with various cellular localization and different contribution to ascorbate recycling [75,76]. Specifically, MDAR6 is targeted to mitochondria or plastids [75], while DHAR2 is localized in the cytosol [76]. Recent studies demonstrated that independent Arabidopsis dhar 2 and mdar6 mutants were not strongly affected on the levels and redox state of ascorbate implying a small contribution of these isoforms to the ascorbate recycling $[77,78]$. It is worthwhile considering that C. quitensis plants have been shown to activate many systems leading to oxidative-stress control as well as $\mathrm{H}_{2} \mathrm{O}_{2}$ reducing reactions that take place independently from ascorbate oxidation. Moreover, the depletion of reduced glutathione by active DHAR, which uses GSH to reduce dehydroascorbate to ascorbate, could impair the activity of HSPs which need GSH to maintain proteins in their functional conformations. This hypothesis is also in line with the observed under-expression of the glutathione peroxidase 6, GPX6 (AT4G11600, $\left.\log _{2} \mathrm{FC}=-2.58\right)$. Interestingly, DHAR2 was found to interact with both MDAR6 and GPX6 using STRING program (Figure S2B).

Overall, we can infer that OTC plants are able to control oxidative stress due to the over-expression of some antioxidant enzymes and a series of temperature-induced proteins known to be involved in maintaining the redox state. The concomitant under-expression of known ROS scavengers can be justified by the need to minimize energy expenditure by channeling energy only on the expression of the isoforms deemed necessary on the basis of the relative substrates and the specific cellular localization.

\subsection{Antioxidant Enzyme Activity Assays}

In order to confirm the hypothesis that OTC plants are able to control oxidative stress damage in a more powerful way than OUT plants, we compared the activity of some antioxidant enzymes in both samples. 
As shown in Figure 6, the activities of catalase (CAT), glutathione S-transferase (GST), guaiacol peroxidase (POD) and superoxide dismutase (SOD) were all significantly higher in OTC samples, which also showed a significantly lower TBARS content entailing a better restraint of lipid peroxidation events. As for SOD, it is worthwhile remembering that its activity was expressed as $\mathrm{IC}_{50}$, corresponding to the amount $(\mu \mathrm{g})$ of total protein extract necessary to inhibit by $50 \%$ the reduction of a tetrazolium salt by the superoxide anion. Thus, low levels of $\mathrm{IC}_{50}$ are related to higher SOD activity. On the other hand, ascorbate peroxidase activity was found to be significantly lower in OTC than OUT plants. Peroxidases are enzymes involved in maintaining $\mathrm{H}_{2} \mathrm{O}_{2}$ homeostasis, together with peroxisomal catalase. In particular, ascorbate peroxidases participate in the removal of $\mathrm{H}_{2} \mathrm{O}_{2}$ as part of the ascorbate-glutathione pathway. Indeed, in this work we found the downregulation of two other enzymes involved in the ascorbate-glutathione pathway, namely MDAR and DHAR, leading to the hypothesis that the whole pathway could be limited in OTC plants. Nevertheless, the over-expression of other enzymes, such as POD, can contribute to the removal of $\mathrm{H}_{2} \mathrm{O}_{2}$ in plants and compensate for the downregulation of APX. In this regard, it has been reported that rice mutants for cytosolic APXs were able to upregulate other peroxidases and to cope with abiotic stress as non-transformed plants [79]. Moreover, we could also infer that OTC plants regulate the electron transport pathway in a way that avoids the reduction of oxygen, thus limiting $\mathrm{ROS}$ and $\mathrm{H}_{2} \mathrm{O}_{2}$ production. In general, our differential proteomic analysis revealed that OTC plants activate many different routes aimed to dissipate the excess of reducing equivalents and avoid ROS production and the over-expression of ROS detoxifying enzymes is a supplementary way to maintain oxidative stress under strict control.

A

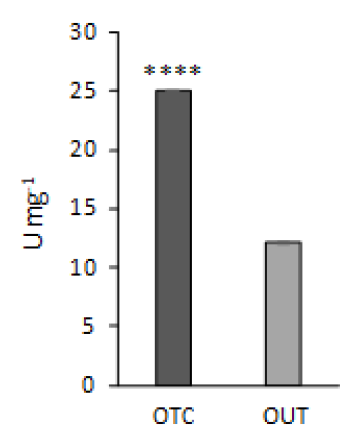

D

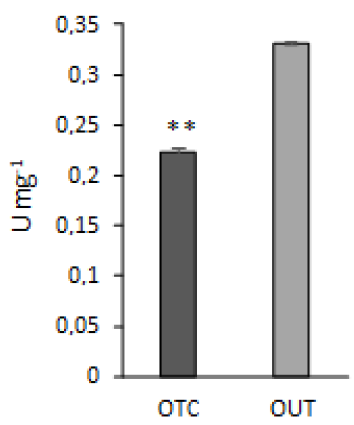

B

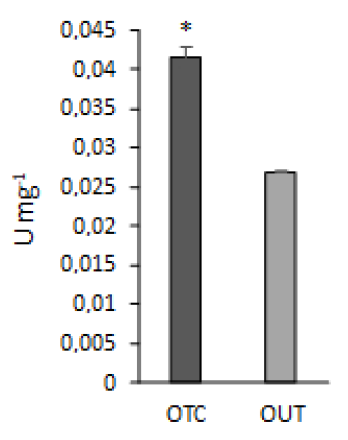

E

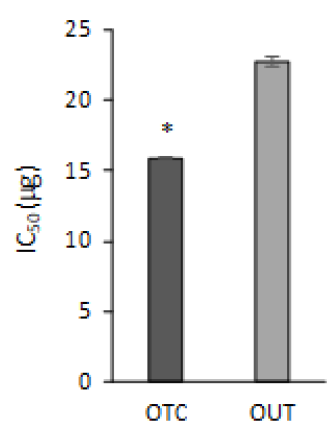

C

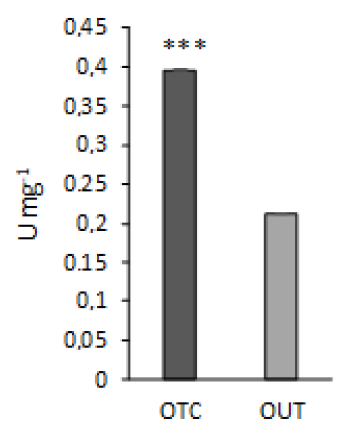

$\mathbf{F}$

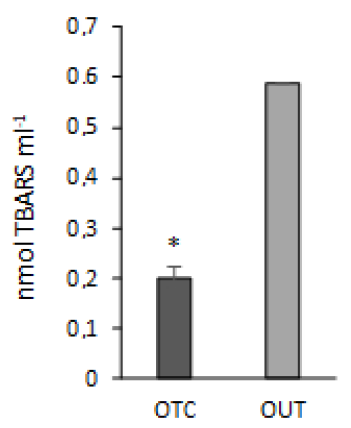

Figure 6. Antioxidant enzyme activities and TBARS content in C. quitensis leaves. (A) Catalase (CAT); (B) glutathione S-transferase (GST); (C) guaiacol peroxidase (POD); (D) ascorbate peroxidase (APX); (E) superoxide dismutase (SOD); (F) TBARS content. Data represent the mean \pm SD from three biological and three technical replicates. Asterisks indicate significant differences (Student $t$-test: $\left.{ }^{*} p<0.05 ;{ }^{* *} p<0.01 ;{ }^{* * *} p<0.001{ }^{* * * *} p<0.00001\right)$. 


\subsection{Warming Influences Carbohydrates Accumulation in C. quitensis}

Carbohydrates play a key role in plant resistance to abiotic stress as they act as osmolytes, maintaining the cell-water balance and membrane stability, antioxidants, and thermoprotectants [80]. Moreover, cell wall polysaccharides provide mechanical integrity to each cell and mediate its interaction either with neighboring cells or the environment [81]. In C. quitensis plants, the sugar content was proved to be strongly affected by abiotic stresses, such as thermal regimen and day length [82], and sucrose concentration in leaves was positively correlated with freezing avoidance [83]. Furthermore, C. quitensis growth inside OTCs was found to reduce the content of cell wall chemical components (cellulose, hemicellulose and lignin), likely allowing a better $\mathrm{CO}_{2}$ diffusion into the leaf mesophyll [12]. Interestingly, in our work, the differential proteomic analysis revealed the under-expression of many enzymes involved in carbohydrates metabolism such as UDP-glucose pyrophosphorylase 1 (UGPase1, AT3G03250, $\log _{2} \mathrm{FC}=-2.87$ ), ADP-glucose pyrophosphorylase (AGPase, AT1G74910, $\log _{2} \mathrm{FC}=-2.84$ ), phosphoglucomutase (AT1G70730, $\log _{2} \mathrm{FC}=-0.94$ ), disproportionating enzyme 2 (DPE2, AT2G40840, $\left.\log _{2} \mathrm{FC}=-4.11\right)$, and UDP glucose/galactose epimerase $5\left(\mathrm{UGE} 5, \log _{2} \mathrm{FC}=-3.01\right)$. In particular, UGPase 1 is capable of activating glucose-1-P (Glc-1P) to UDP-glucose (UDP-Glc) that can be used for sucrose as well as cell wall polysaccharides biosynthesis; AGPase plays a role in the starch biosynthesis catalyzing the synthesis of ADP-Glc from Glc-1P; phosphoglucomutase drives the synthesis of Glc-1P from Glc-6P which can be utilized in both the above pathways; DPE2 catalyzes the cytosolic conversion of maltose into glucose, which can be used for sucrose biosynthesis; and UGE5 appears to be mainly involved in the generation of UDP-Galactose from UDP-Glc to generate building blocks for cell wall carbohydrates biosynthesis [84]. Furthermore, in Arabidopsis, the isoform UGE5 was also found to be induced by abscisic acid, salt, and temperature stress, and was hypothesized to act in stress situations by supplying UDP-galactose for the biosynthesis of the osmoprotectant galactinol [84]. All in all, these findings reveal that warming slows down carbohydrate metabolism in C. quitensis plants and this event may impair plant freezing resistance, due to the important role of sugar metabolites as cryo-protectants and as adaptive biochemical factors in osmo-protection during abiotic stress. Indeed, it has been recently demonstrated that warmer conditions enhance the freezing vulnerability of both Antarctic species increasing their $\mathrm{LT}_{50}$ (freezing temperature producing $50 \%$ photoinactivation) [13]. Similar responses were also reported for temperate and arctic plants where warming altered freezing tolerance and influenced plant physiology, including carbon metabolism [85]. In addition, our results are consistent with that already reported [12] who highlighted reduced fiber content in the cell wall of C. quitensis grown inside OTCs. In this regard, it is worthwhile mentioning that in this work we also found the downregulation of the cynnamil-alcohol dehydrogenase CAD1 (AT1G72680, $\log _{2} \mathrm{FC}=-2.64$ ), involved in lignin biosynthesis, strengthening the evidence that warming reduces the deposition of cell wall components.

\section{Conclusions}

In conclusion, our analysis revealed that OTCs plants have a high rate of photorespiration which acts as a protective mechanism against photooxidative damage and ROS production (Figure 7). Moreover, C. quitensis plants grown inside OTCs seemed to control the oxidative stress more efficiently than the counterpart grown in open field by means of scavengers which detoxify ROS and limit lipid peroxidation. Furthermore, the carbohydrates metabolism reprogramming could lead to reducing the deposition of cell wall polysaccharides, probably improving $\mathrm{CO}_{2}$ diffusion into the mesophyll and therefore the photosynthetic efficiency. Hence, it seems that OTCs growth is beneficial for C. quitensis plants, which come closer to their optimal temperature for net photosynthesis, although the drawback is a reduced freezing tolerance due to lower concentration of soluble sugars which act as osmoprotectants. 


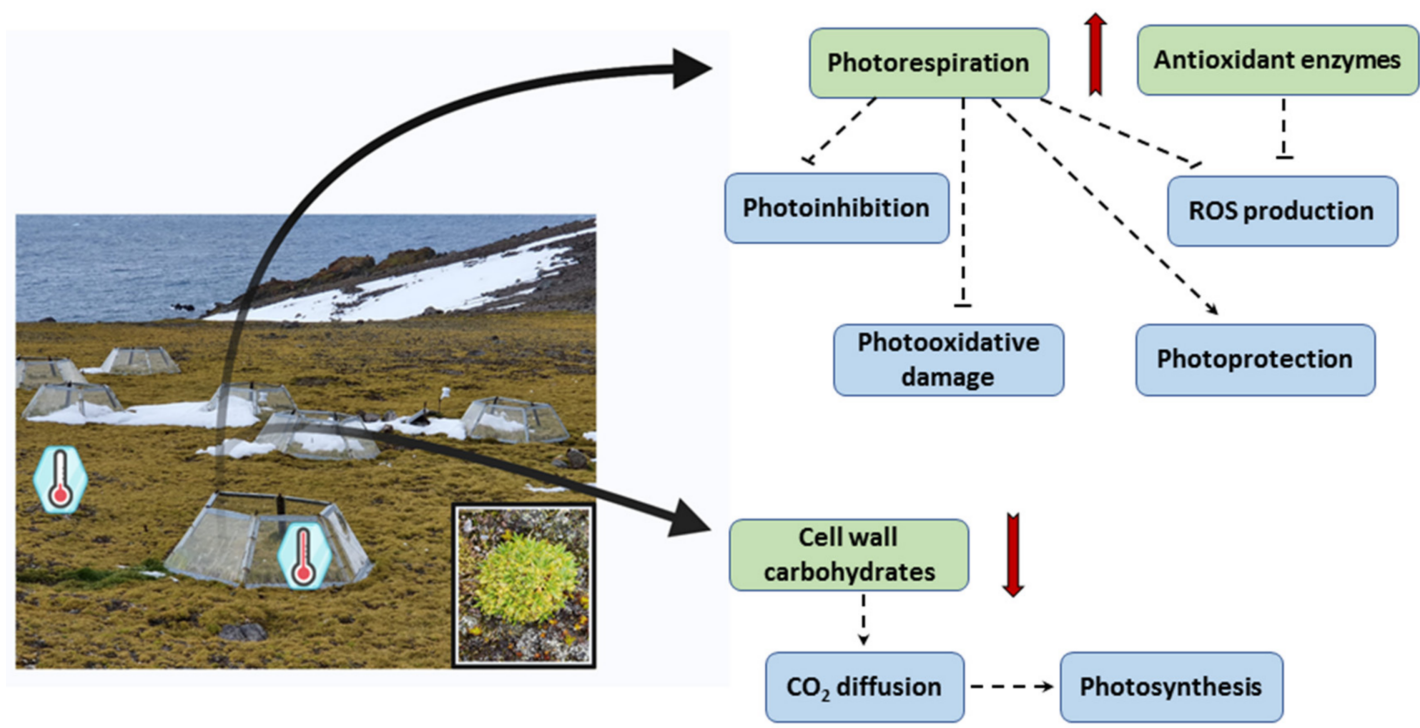

Figure 7. Outline of the main results obtained in the present paper. Continuous red arrows: obtained results; dashed black arrows: inferred information. The figure was created with BioRender.com, accessed on 20 April 2021.

Supplementary Materials: The following are available online at https:/ / www.mdpi.com/article/10 .3390 /biom11081094/s1, Figure S1: Melting curves of psbA (PSII protein D1) and vde (violaxanthin de-epoxidase) genes, Figure S2: The protein-protein interaction network of differentially expressed proteins (DEPs) in OTC vs. OUT C. quitensis leaf samples, Table S1: List of primers used in the study and related information, Table S2: Complete protein table obtained by MaxQuant using the in-house built C. quitensis protein database, Table S3: Complete protein table obtained by MaxQuant using the Viridiplantae database, Table S4: List of the differentially expressed proteins.

Author Contributions: Conceptualization, C.C. and L.B.; methodology, C.C., L.B., M.M. and P.F.; software, P.F. and R.S.; validation, L.B. and C.C.; formal analysis, F.C., I.I., R.S., L.B. and S.P.; investigation, F.C., I.I., R.S., L.B., S.P. and G.S.F.; resources, C.C., M.M. and P.F.; data curation, C.C., L.B., M.M. and P.F.; writing-original draft preparation, L.B., C.C., M.M. and P.F.; writing-review and editing, C.C., L.B., M.M., P.F., S.P. and F.C.; visualization, L.B., C.C., M.M. and P.F.; supervision, C.C. and M.M.; project administration, C.C.; funding acquisition, C.C. All authors have read and agreed to the published version of the manuscript.

Funding: This research was funded by Ministero dell'Istruzione, Università e Ricerca Scientifica (MIUR) in the framework of the PNRA (National Program for Antarctic Research), grant number 2013/C1.02.

Data Availability Statement: LC-MS/MS raw data are available in the ProteomeXchange repository, using the following identifiers: Project Name: Colobanthus quitensis differential proteomics; Project accession: PXD027038.

Acknowledgments: The authors thank Leon Bravo from Universidad de La Frontera, Temuco, Chile, who installed the OTCs in Antarctica in 2012 and allowed us to collect leaf samples from inside. The authors also thank the INACH (Instituto Antártico Chileno) for the logistic support from Chile to King George Island and vice versa and the members of Arctowski Research Station for their great hospitality and their collaboration with the logistics. Moreover, the authors thank Fabio Fruggiero of University of Basilicata for his support in the organization of the C. quitensis protein database.

Conflicts of Interest: The authors declare no conflict of interest. The funders had no role in the design of the study; in the collection, analyses, or interpretation of data; in the writing of the manuscript; or in the decision to publish the results. 


\section{References}

1. Vaughan, D.G.; Marshall, G.J.; Connolley, W.M.; Parkinson, C.; Mulvaney, R.; Hodgson, D.A.; King, J.C.; Pudsey, C.J.; Turner, J. Recent rapid regional climate warming on the Antarctic Peninsula. Clim. Chang. 2003, 60, 243-274. [CrossRef]

2. Turner, J.; Colwell, S.R.; Marshall, G.J.; Lachlan-Cope, T.A.; Carleton, A.M.; Jones, P.D.; Lagun, V.; Reid, P.A.; Iagovkina, S. Antarctic climate change during the last 50 years. Int. J. Climatol. 2005, 25, 279-294. [CrossRef]

3. Smith, R.I.L. The enigma of Colobanthus quitensis and Deschampsia antarctica in Antarctica. In Antarctic Biology in a Global Context; Huiskes, A.H.L., Gieskes, W.W.C., Rozema, J., Schorno, R.M.L., van der Vies, S.M., Wolff, W.J., Eds.; Backhuys Publishers: Leiden, The Netherlands, 2003; pp. 234-239.

4. Sáez, P.L.; Bravo, L.A.; Cavieres, L.A.; Vallejos, V.; Sanhueza, C.; Font-Carrascosa, M.; Gil-Pelegrín, E.; Peguero-Pina, J.J.; Galmés, J. Photosynthetic limitations in Antarctic vascular plants: Importance of the leaf anatomical traits and Rubisco kinetics parameters. J. Exp. Bot. 2017, 68, 2871-2883. [CrossRef]

5. Cavieres, L.A.; Sáez, P.; Sanhueza, C.; Sierra-Almeida, A.; Rabert, C.; Corcuera, L.J.; Bravo, L.A. Ecophysiological traits of Antarctic vascular plants: Their importance in the responses to climate change. Plant Ecol. 2016, 217, 343-358. [CrossRef]

6. Torres-Díaz, C.; Gallardo-Cerda, J.; Lavin, P.; Oses, R.; Carrasco-Urra, F.; Atala, C.; Acuña-Rodríguez, I.S.; Convey, P.; MolinaMontenegro, M.A. Biological interactions and simulated climate change modulates the ecophysiological performance of Colobanthus quitensis in the Antarctic ecosystem. PLoS ONE 2016, 11, e0164844. [CrossRef]

7. Nibert, M.L.; Manny, A.R.; Debat, H.J.; Firth, A.E.; Bertini, L.; Caruso, C. A barnavirus sequence mined from a transcriptome of the Antarctic pearlwort Colobanthus quitensis. Arch. Virol. 2018, 163, 1921-1926. [CrossRef]

8. Ballesteros, G.I.; Torres-Díaz, C.; Bravo, L.A.; Balboa, K.; Caruso, C.; Bertini, L.; Proietti, S.; Molina-Montenegro, M.A. In silico analysis of metatranscriptomic data from the Antarctic vascular plant Colobanthus quitensis: Responses to a global warming scenario through changes in fungal gene expression levels. Fungal. Ecol. 2020, 43, 100873. [CrossRef]

9. Torres-Mellado, G.A.; Jaña, R.; Casanova-Katny, M.A. Antarctic hairgrass expansion in the South Shetland archipelago and Antarctic Peninsula revisited. Polar Biol. 2011, 34, 1679-1688. [CrossRef]

10. Cannone, N.; Guglielmin, M.; Convey, P.; Worland, M.R.; Favero Longo, S.E. Vascular plant changes in extreme environments: Effects of multiple drivers. Clim. Chang. 2016, 134, 651-665. [CrossRef]

11. Day, T.A.; Ruhland, C.T.; Xiong, F.S. Warming increases aboveground plant biomass and C stocks in vascular-plant dominated Antarctic tundra. Glob. Chang. Biol. 2008, 14, 1827-1843. [CrossRef]

12. Sáez, P.L.; Cavieres, L.A.; Galmés, J.; Gil-Pelegrín, E.; Peguero-Pina, J.J.; Sancho-Knapik, D.; Vivas, M.; Sanhueza, C.; Ramírez, C.F.; Rivera, B.K.; et al. In situ warming in the Antarctic: Effects on growth and photosynthesis in the Antarctic vascular plants. New Phytol. 2018, 218, 1406-1418. [CrossRef]

13. Sierra-Almeida, A.; Cavieres, L.A.; Bravo, L.A. Warmer Temperatures Affect the in situ Freezing Resistance of the Antarctic Vascular Plants. Front. Plant Sci. 2018, 9, 1456. [CrossRef] [PubMed]

14. Turner, J.; Lu, H.; White, I.; King, J.C.; Phillips, T.; Hosking, J.S.; Bracegirdle, T.J.; Marshall, G.J.; Mulvaney, R.; Deb, P. Absence of 21st century warming on Antarctic Peninsula consistent with natural variability. Nature 2016, 535, 411-415. [CrossRef] [PubMed]

15. Clemente-Moreno, M.J.; Omranian, N.; Sáez, P.; Figueroa, C.M.; Del-Saz, N.; Elso, M.; Poblete, L.; Orf, I.; Cuadros-Inostroza, A.; Cavieres, L.; et al. Cytochrome respiration pathway and sulphur metabolism sustain stress tolerance to low temperature in the Antarctic species Colobanthus quitensis. New Phytol. 2020, 225, 754-768. [CrossRef] [PubMed]

16. Arthofer, W.; Bertini, L.; Caruso, C.; Cicconardi, F.; Delph, L.F.; Fields, P.D.; Ikeda, M.; Minegishi, Y.; Proietti, S. Transcriptome sequencing of the Antarctic Colobanthus quitensis (Kunth) Bartl (Caryophillaceae). Mol. Ecol. Resour. 2015, 15, 1014-1015. [CrossRef]

17. Hollister, R.D.; Webber, P.J. Biotic validation of small open-top chambers in a tundra ecosysem. Glob. Chang. Biol. 2000, 6, 835-842. [CrossRef]

18. Bokhorst, S.; Huiskes, A.; Aerts, R.; Convey, P.; Cooper, E.J.; Dalen, L.; Erschbamer, B.; Gudmundsson, J.; Hofgaard, A.; Hollister, R.D.; et al. Variable temperature effects of Open Top Chambers at polar and alpine sites explained by irradiance and snow depth. Glob. Chang. Biol. 2013, 19, 64-74. [CrossRef]

19. Bradford, M.M. A rapid sensitive method for the quantification of microgram quantities of protein utilizing the principle of protein-dye binding. Anal. Biochem. 1976, 72, 248-254. [CrossRef]

20. Laemmli, U. Cleavage of Structural Proteins during the Assembly of the Head of Bacteriophage T4. Nature 1970, 227, 680-685. [CrossRef]

21. Iaconis, D.; Monti, M.; Renda, M.; van Koppen, A.; Tammaro, R.; Chiaravalli, M.; Cozzolino, F.; Pignata, P.; Crina, C.; Pucci, P.; et al. The centrosomal OFD1 protein interacts with the translation machinery and regulates the synthesis of specific targets. Sci. Rep. 2017, 7, 1224. [CrossRef]

22. Cozzolino, F.; Landolfi, A.; Iacobucci, I.; Monaco, V.; Caterino, M.; Celentano, S.; Zuccato, C.; Cattaneo, E.; Monti, M. New Label-Free Methods for Protein Relative Quantification Applied to the Investigation of an Animal Model of Huntington Disease. PLoS ONE 2020, 15, e0238037. [CrossRef]

23. Goedhart, J.; Luijsterburg, M.S. VolcaNoseR Is a Web App for Creating, Exploring, Labeling and Sharing Volcano Plots. Sci. Rep. 2020, 10, 20560. [CrossRef]

24. Du, Z.; Zhou, X.; Ling, Y.; Zhang, Z.; Su, Z. AgriGO: A GO analysis toolkit for the agricultural community. Nucleic Acids Res. 2010, 38, W64-W70. [CrossRef] [PubMed] 
25. Szklarczyk, D.; Morris, J.H.; Cook, H.; Kuhn, M.; Wyder, S.; Simonovic, M. The STRING database in 2017: Quality-controlled protein-protein association networks, made broadly accessible. Nucl. Acids Res. 2017, 45, D362-D368. [CrossRef] [PubMed]

26. Bertini, L.; Focaracci, F.; Proietti, S.; Papetti, P.; Caruso, C. Physiological response of Posidonia oceanica to heavy metal pollution along the Tyrrhenian coast. Funct. Plant Biol. 2019, 46, 933-941. [CrossRef]

27. Bertini, L.; Proietti, S.; Focaracci, F.; Canini, F.; Bravo, L.A.; Rabert, C.; Caruso, C. Identification and validation of new reference genes for accurate quantitative reverse transcriptase-PCR normalization in the Antarctic plant Colobanthus quitensis under abiotic stress conditions. Polar Biol. 2021, 44, 389-405. [CrossRef]

28. Laurino, S.; Grossi, G.; Pucci, P.; Flagiello, A.; Bufo, S.A.; Bianco, G.; Salvia, R.; Vinson, B.S.; Vogel, H.; Falabella, P. Identification of major Toxoneuron nigriceps venom proteins using an integrated transcriptomic/proteomic approach. Insect Biochem. Mol. Biol. 2016, 76, 49-61. [CrossRef]

29. Soto-Suárez, M.; Serrato, A.J.; Rojas-González, J.A.; Bautista, R.; Sahrawy, M. Transcriptomic and proteomic approach to identify differentially expressed genes and proteins in Arabidopsis thaliana mutants lacking chloroplastic 1 and cytosolic FBPases reveals several levels of metabolic regulation. BMC Plant Biol. 2016, 16, 258. [CrossRef]

30. Scieuzo, C.; Salvia, R.; Franco, A.; Pezzi, M.; Cozzolino, F.; Chicca, M.; Scapoli, C.; Vogel, H.; Monti, M.; Ferracini, C.; et al. An integrated transcriptomic and proteomic approach to identify the main Torymus sinensis venom components. Sci. Rep. 2021, M. [CrossRef] [PubMed]

31. Balbi, V.; Devoto, A. Jasmonate signalling network in Arabidopsis thaliana: Crucial regulatory nodes and new physiological scenarios. New Phytol. 2008, 177, 301-318. [CrossRef]

32. Convey, P. Antarctic terrestrial ecosystems: Responses to environmental changes. Polarforsch 2006, 75, $101-111$.

33. Xiong, F.S.; Ruhland, T.C.; Day, T.A. Photosynthetic temperature response of the Antarctic vascular plants Colobanthus quitensis and Deschampsia antarctica. Physiol. Plant. 1999, 106, 276-286. [CrossRef]

34. Derks, A.; Schaven, K.; Bruce, D. Diverse mechanisms for photoprotection in photosynthesis. Dynamic regulation of photosystem II excitation in response to rapid environmental change. Biochim. Biophys. Acta 2015, 1847, 468-485. [CrossRef]

35. Voss, I.; Sunil, B.; Scheibe, R.; Raghavendra, A.S. Emerging concept for the role of photorespiration as an important part of abiotic stress response. Plant Biol. 2013, 15, 713-722. [CrossRef]

36. Sunil, B.; Saini, D.; Bapatla, R.B.; Aswani, V.; Raghavendra, A.S. Photorespiration is complemented by cyclic electron flow and the alternative oxidase pathway to optimize photosynthesis and protect against abiotic stress. Photosynth. Res. 2019, 139, 67-79. [CrossRef]

37. Bauwe, H.; Hagemann, M.; Kern, R.; Timm, S. Photorespiration has a dual origin and manifold links to central metabolism. Curr Opin. Plant Biol. 2012, 15, 269-275. [CrossRef]

38. Foyer, C.H.; Bloom, A.J.; Queval, G.; Noctor, G. Photorespiratory metabolism: Genes, mutants, energetics, and redox signaling. Annu. Rev. Plant Biol. 2009, 60, 455-484. [CrossRef]

39. Walker, B.J.; Strand, D.D.; Kramer, D.M.; Cousins, A.B. The response of cyclic electron flow around photosystem I to changes in photorespiration and nitrate assimilation. Plant Physiol. 2014, 165, 453-462. [CrossRef]

40. Selinski, J.; Scheibe, R. Malate valves: Old shuttles with new perspectives. Plant Biol. 2019, 21, 21-30. [CrossRef]

41. Bykova, N.V.; Møller, I.M.; Gardeström, P.; Igamberdiev, A.U. The function of glycine decarboxylase complex is optimized to maintain high photorespiratory flux via buffering of its reaction products. Mitochondrion 2014, 19, 357-364. [CrossRef]

42. Tomaz, T.; Bagard, M.; Pracharoenwattana, I.; Lindén, P.; Lee, C.P.; Carroll, A.J.; Ströher, E.; Smith, S.M.; Gardeström, P.; Millar, A.H. Mitochondrial malate dehydrogenase lowers leaf respiration and alters photorespiration and plant growth in Arabidopsis. Plant Physiol. 2010, 154, 1143-1157. [CrossRef]

43. Timm, S.; Florian, A.; Jahnke, K.; Nunes-Nesi, A.; Fernie, A.R.; Bauwe, H. The hydroxypyruvate-reducing system in Arabidopsis: Multiple enzymes for the same end. Plant Physiol. 2011, 155, 694-705. [CrossRef]

44. Timm, S.; Wittmiß, M.; Gamlien, S.; Ewald, R.; Florian, A.; Frank, M.; Wirtz, M.; Hell, R.; Fernie, A.R.; Bauwe, H. Mitochondrial dihydrolipoyl dehydrogenase activity shapes photosynthesis and photorespiration of Arabidopsis thaliana. Plant Cell 2015, 27, 1968-1984. [CrossRef]

45. Peterhänsel, C.; Krause, K.; Braun, H.P.; Espie, G.S.; Fernie, A.R.; Hanson, D.T.; Keech, O.; Maurino, V.G.; Mielewczik, M.; Sage, R.F. Engineering photorespiration: Current state and future possibilities. Plant Biol. 2013, 15, 754-758. [CrossRef]

46. Aliyev, J.A. Photosynthesis, photorespiration and productivity of wheat and soybean genotypes. Physiol. Plant. 2012, 145, 369-383. [CrossRef]

47. Hagemann, M.; Fernie, A.R.; Espie, G.S.; Kern, R.; Eisenhut, M.; Reumann, S.; Bauwe, H.; Weber, A.P.M. Evolution of the biochemistry of the photorespiratory C2 cycle. Plant Biol. 2013, 15, 639-647. [CrossRef]

48. Foyer, C.H.; Noctor, G. Oxygen processing in photosynthesis: Regulation and signalling. New Phytol. 2000, 146, 359-388. [CrossRef]

49. Pérez-Torres, E.; Bravo, L.A.; Corcuera, L.J.; Johnson, G.N. Is electron transport to oxygen an important mechanism in photoprotection? Contrasting responses from Antarctic vascular plants. Physiol. Plant. 2007, 130, 185-194. [CrossRef]

50. Bascuñán-Godoy, L.; Sanhueza, C.; Cuba, M.; Zuñiga, G.E.; Corcuera, L.J.; Bravo, L.A. Cold-acclimation limits low temperature induced photoinhibition by promoting a higher photochemical quantum yield and a more effective PSII restoration in darkness in the Antarctic rather than the Andean ecotype of Colobanthus quitensis Kunt Bartl (Cariophyllaceae). BMC Plant Biol. 2012, 12, 114. [CrossRef] 
51. Bai, J.; Xu, D.H.; Kang, H.M.; Chen, K.; Wang, G. Photoprotective function of photorespiration in Reaumuria soongorica during different levels of drought stress in natural high irradiance. Photosynthetica 2008, 46, 232. [CrossRef]

52. Guan, X.; Gu, S. Photorespiration and photoprotection of grapevine (Vitis vinifera L. cv. Cabernet Sauvignon) under water stress. Photosynthetica 2009, 47, 437. [CrossRef]

53. Zhang, C.; Zhan, D.-X.; Luo, H.-H.; Zhang, Y.-L.; Zhang, W.-F. Photorespiration and photoinhibition in the bracts of cotton under water stress. Photosynthetica 2016, 54, 12-18. [CrossRef]

54. Langer, T. AAA proteases: Cellular machines for degrading membrane proteins. Trends Biochem. Sci. 2000, 25, 247-251. [CrossRef]

55. Sokolenko, A.; Pojidaeva, E.; Zinchenko, V.; Panichkin, V.; Glaser, V.M.; Herrmann, R.G.; Shestakov, S.V. The gene complement for proteolysis in the cyanobacterium Synechocystis sp. PCC 6803 and Arabidopsis thaliana chloroplasts. Curr. Genet. 2002, 41, 291-310. [CrossRef]

56. Sakamoto, W.; Miura, E.; Kaji, Y.; Okuno, T.; Nishizono, M.; Ogura, T. Allelic characterization of the leaf-variegated mutation var2 identifies the conserved amino acid residues of FtsH that are important for ATP hydrolysis and proteolysis. Plant Mol. Biol. 2004, 56, 705-716. [CrossRef]

57. Kato, Y.; Miura, E.; Ido, K.; Ifuku, K.; Sakamoto, W. The variegated mutants lacking chloroplastic FtsHs are defective in D1 degradation and accumulate reactive oxygen species. Plant Physiol. 2009, 151, 1790-1801. [CrossRef]

58. Sinvany-Villalobo, G.; Davydov, O.; Ben-Ari, G.; Zaltsman, A.; Raskind, A.; Adam, Z. Expression in multigene families. Analysis of chloroplast and mitochondrial proteases. Plant Physiol. 2004, 135, 1336-1345. [CrossRef]

59. Wang, F.; Qi, Y.; Malnoe, A.; Choquet, Y.; Wollman, F.A.; De Vitry, C. The high light response and redox control of thylakoid FtsH protease in Chlamydomonas Reinhardtii. Mol. Plant 2017, 10, 99-114. [CrossRef]

60. Adamska, I. The Elip family of stress proteins in the thylakoid membranes of pro- and eukaryota. In Advances in Photosynthesis and Respiration-Regulation of Photosynthesis; Aro, E.M., Andersson, B., Eds.; Kluwer Academic Publishers: Dordrecht, The Netherlands, 2001; Volume 11, pp. 487-505. [CrossRef]

61. Andersson, U.; Heddad, M.; Adamska, I. Light stress-induced one-helix protein of the chlorophyll $a / b$-binding family associated with photosystem I. Plant Physiol. 2003, 132, 811-820. [CrossRef]

62. Hutin, C.; Nussaume, L.; Moise, N.; Moya, I.; Kloppstech, K.; Havaux, M. Early light-induced proteins protect Arabidopsis from photooxidative stress. Proc. Natl. Acad. Sci. USA 2003, 100, 4921-4926. [CrossRef]

63. Zarter, C.R.; Adams, W.W., 3rd; Ebbert, V.; Adamska, I.; Jansson, S.; Demmig-Adams, B. Winter acclimation of PsbS and related proteins in the evergreen Arctostaphylos uva-ursi as influenced by altitude and light environment. Plant Cell Environ. 2006, 29, 869-878. [CrossRef] [PubMed]

64. Jin, E.S.; Polle, J.E.W.; Melis, A. Involvement of zeaxanthin and of the Cbr protein in the repair of photosystem II from photoinhibition in the green alga Dunaliella salina. Biochim. Biophys. Acta 2001, 1506, 244-259. [CrossRef]

65. Jin, E.S.; Yokthongwattana, K.; Polle, J.E.W.; Melis, A. Role of the reversible xanthophyll cycle in the photosystem II damage and repair cycle in Dunaliella salina. Plant Physiol. 2003, 132, 352-364. [CrossRef]

66. Niyogi, K.K. Safety valves for photosynthesis. Curr. Opin. Plant Biol. 2000, 3, 455-466. [CrossRef]

67. Akerstrom, B.; Flower, D.R.; Salier, J.-P. Lipocalins: Unity in diversity. BBA Protein Struct M 2000, 1482, 1-8. [CrossRef]

68. Charron, J.B.; Ouellet, F.; Pelletier, H.; Danyluk, J.; Chauve, C.; Sarhan, F. Identification, expression, and evolutionary analyses of plant lipocalins. Plant Physiol. 2005, 139, 2017-2028. [CrossRef]

69. Boca, S.; Koestler, F.; Ksas, B.; Chevalier, A.; Leymarie, J.; Fekete, A.; Mueller, M.J.; Havaux, M. Arabidopsis lipocalins AtCHL and AtTIL have distinct but overlapping functions essential for lipid protection and seed longevity. Plant Cell Environ. 2014, 37, 368-381. [CrossRef]

70. Chi, W.T.; Fung, R.W.; Liu, H.C.; Hsu, C.C.; Chamg, Y.Y. Temperature-induced lipocalin is required for basal and acquired thermotolerance in Arabidopsis. Plant Cell Environ. 2009, 32, 917-927. [CrossRef]

71. Wang, W.; Vinocur, B.; Shoseyov, O.; Altman, A. Role of plant heat-shock proteins and molecular chaperones in the abiotic stress response. Trends Plant Sci. 2004, 9, 244-252. [CrossRef] [PubMed]

72. Kalmar, B.; Greensmith, L. Induction of heat shock proteins for protection against oxidative stress. Adv. Drug Deliv. Rev. 2009, 61, 310-318. [CrossRef]

73. Larkindale, J.; Mishkind, M.; Vierling, E. Plant responses to high temperature. In Plant Abiotic Stress; Jenks, M.A., Hasegawa, P.M., Eds.; Blackwell Publishing: Hoboken, NY, USA, 2005; pp. 100-144. [CrossRef]

74. Obara, K.; Sumi, K.; Fukuda, H. The use of multiple transcription starts causes the dual targeting of Arabidopsis putative monodehydroascorbate reductase to both mitochondria and chloroplasts. Plant Cell Physiol. 2002, 43, 697-705. [CrossRef]

75. Dixon, D.P.; Davis, B.G.; Edwards, R. Functional divergence in the glutathione transferase superfamily in plants: Identification of two classes with putative functions in redox homeostasis in Arabidopsis thaliana. J. Biol. Chem. 2002, 277, 30859-30869. [CrossRef]

76. Johnston, E.J.; Rylott, E.L.; Beynon, E.; Lorenz, A.; Chechik, V.; Bruce, N.C. Monodehydroascorbate reductase mediates TNT toxicity in plants. Science 2015, 349, 1072-1075. [CrossRef]

77. Rahantaniaina, M.S.; Li, S.; Chatel-Innocenti, G.; Tuzet, A.; Issakidis-Bourguet, E.; Mhamdi, A.; Noctor, G. Cytosolic and Chloroplastic DHARs Cooperate in Oxidative Stress-Driven Activation of the Salicylic Acid Pathway. Plant Physiol. 2017, 174, 956-971. [CrossRef] [PubMed] 
78. Bonifacio, A.; Martins, M.O.; Ribeiro, C.W.; Fontenele, A.V.; Carvalho, F.E.L.; Margis-Pinheiro, M.; Silveira, J.A.G. Role of peroxidases in the compensation of cytosolic ascorbate peroxidase knockdown in rice plants under abiotic stress. Plant Cell Environ. 2011, 34, 1705-1722. [CrossRef] [PubMed]

79. Xalxo, R.; Yadu, B.; Chandra, J.; Chandrakar, V.; Keshavkant, S. Alteration in carbohydrate metabolism modulates thermotolerance of plant under heat stress. In Heat Stress Tolerance in Plants: Physiological, Molecular and Genetic Perspectives, 1st ed.; Wani, S.H., Kumar, V., Eds.; John Wiley \& Sons Ltd.: Hoboken, NJ, USA, 2020. [CrossRef]

80. Somerville, C.R.; Bauer, S.; Brininstool, G.; Facette, M.; Hamann, T.; Milne, J.; Osborne, E.; Paredez, A.; Persson, S.; Raab, T.; et al. Toward a systems approach to understanding plant cell walls. Science 2004, 306, 2206-2211. [CrossRef] [PubMed]

81. Zúñiga-Feest, A.; Bascuñán-Godoy, L.; Reyes-Diaz, M.; Bravo, L.A.; Corcuera, L.J. Is survival after ice encasement related with sugar distribution in organs of the Antarctic plants Deschampsia antarctica Desv. (Poaceae) and Colobanthus quitensis (Kunth) Bartl. (Caryophyllaceae)? Polar Biol. 2009, 32, 583-591. [CrossRef]

82. Bravo, L.A.; Ulloa, N.; Zúñiga, G.E.; Casanova, A.; Corcuera, L.J.; Alberdi, M. Cold resistance in Antarctic angiosperms. Physiol. Plant. 2001, 111, 55-65. [CrossRef]

83. Rösti, J.; Barton, C.J.; Albrecht, S.; Dupree, P.; Pauly, M.; Findlay, K.; Roberts, K.; Seiferta, G.J. UDP-Glucose 4-Epimerase Isoforms UGE2 and UGE4 Cooperate in Providing UDP-Galactose for Cell Wall Biosynthesis and Growth of Arabidopsis thaliana. Plant Cell 2007, 19, 1565-1579. [CrossRef]

84. Bokhorst, S.; Bjerke, J.W.; Davey, M.P.; Taulavuori, K.; Taulavuori, E.; Laine, K.; Callaghan, T.V.; Gareth, K.P. Impacts of extreme winter warming events on plant physiology in a sub-Arctic heath community. Physiol. Plant. 2010, 140, 128-140. [CrossRef]

85. Pagter, M.; Andersen, U.B.; Andersen, L. Winter warming delays dormancy release, advances budburst, alters carbohydrate metabolism and reduces yield in a temperate shrub. AoB Plants 2015, 7, plv024. [CrossRef] [PubMed] 